\title{
Impact of London's road traffic air and noise pollution on birth weight: retrospective population based cohort study
}

\author{
Rachel B Smith, ${ }^{1,2}$ Daniela Fecht, ${ }^{3}$ John Gulliver, ${ }^{1}$ Sean D Beevers, ${ }^{4}$ David Dajnak, ${ }^{4}$ \\ Marta Blangiardo, ${ }^{1}$ Rebecca E Ghosh, ${ }^{3}$ Anna L Hansell, ${ }^{2,3}$ Frank J Kelly, ${ }^{2,4}$ H Ross Anderson, ${ }^{4,5}$ \\ Mireille B Toledano ${ }^{1,2}$
}

\begin{abstract}
${ }^{1}$ MRC-PHE Centre for
\end{abstract}
Environment and Health,

Department of Epidemiology

and Biostatistics, School of

Public Health, Imperial College

London, St Mary's Campus,

Norfolk Place, London W2

1PG, UK

${ }^{2} \mathrm{NIHR}$ HPRU in Health Impact of Environmental Hazards, King's

College London, London, UK

${ }^{3}$ UK Small Area Health Statistics Unit, MRC-PHE Centre for

Environment and Health,

Department of Epidemiology

and Biostatistics, School of

Public Health, Imperial College

London, London, UK

${ }^{4}$ MRC-PHE Centre for

Environment and Health,

Environmental Research

Group, Faculty of Life Sciences

and Medicine, King's College

London, London, UK

${ }^{5}$ Population Health Research

Institute, St George's, University

of London, London, UK

Correspondence to:

M B Toledano

m.toledano@imperial.ac.uk

Additional material is published online only. To view please visit

the journal online.

Cite this as: BMJ 2017;359:j5299

http://dx.doi.org/10.1136/bmi.j5299

Accepted: 1 November 2017

\section{ABSTRACT}

OBJECTIVE

To investigate the relation between exposure to both air and noise pollution from road traffic and birth weight outcomes.

DESIGN

Retrospective population based cohort study.

SETTING

Greater London and surrounding counties up to the M25 motorway (2317 km²), UK, from 2006 to 2010.

PARTICIPANTS

540365 singleton term live births.

MAIN OUTCOME MEASURES

Term low birth weight (LBW), small for gestational age (SGA) at term, and term birth weight.

\section{RESULTS}

Average air pollutant exposures across pregnancy were $41 \mu \mathrm{g} / \mathrm{m}^{3}$ nitrogen dioxide $\left(\mathrm{NO}_{2}\right), 73 \mu \mathrm{g} / \mathrm{m}^{3}$ nitrogen oxides $\left(\mathrm{NO}_{\mathrm{x}}\right), 14 \mu \mathrm{g} / \mathrm{m}^{3}$ particulate matter with aerodynamic diameter $<2.5 \mu \mathrm{m}\left(\mathrm{PM}_{2.5}\right), 23 \mu \mathrm{g} /$ $\mathrm{m}^{3}$ particulate matter with aerodynamic diameter $<10$ $\mu \mathrm{m}\left(\mathrm{PM}_{10}\right)$, and $32 \mu \mathrm{g} / \mathrm{m}^{3}$ ozone $\left(\mathrm{O}_{3}\right)$. Average daytime $\left(\mathrm{L}_{\text {Aeq,16hr }}\right)$ and night-time $\left(\mathrm{L}_{\text {night }}\right)$ road traffic A-weighted noise levels were $58 \mathrm{~dB}$ and $53 \mathrm{~dB}$ respectively. Interquartile range increases in $\mathrm{NO}_{2}, \mathrm{NO}_{x}, \mathrm{PM}_{2.5}, \mathrm{PM}_{10}$, and source specific $P M_{2.5}$ from traffic exhaust $\left(P M_{2.5}\right.$ traffic ${ }_{\text {exhaus) }}$ ) and traffic non-exhaust (brake or tyre wear and resuspension) $\left(\mathrm{PM}_{2.5 \text { traffic non-exhaust }}\right)$ were associated with $2 \%$ to $6 \%$ increased odds of term LBW, and $1 \%$ to $3 \%$

\section{WHAT IS ALREADY KNOWN ON THIS TOPIC}

Road traffic pollution comprises not only air pollutants such as $\mathrm{NO}_{2}$ and particulate matter, but also noise

There is a large body of research demonstrating associations between maternal exposure to ambient air pollution during pregnancy and reduced birth weight, low birth weight (LBW) or small for gestational age (SGA)

The relation between road traffic noise and birth weight is unclear, and research examining traffic related air pollutant and noise coexposures together is very limited, so the extent to which observed air pollution associations might be attributable to road traffic noise is poorly understood

\section{WHAT THIS STUDY ADDS}

There is an increased risk of LBW specifically in relation to the air pollution profile of London

Exposure to local air pollution from road traffic is associated with increased risk of LBW in London, but there is little evidence for an independent exposureresponse effect of traffic related noise on birth weight

Reducing exposure to traffic related air pollution could reduce the burden of LBW, SGA, and subsequent morbidity, and ultimately give babies in urban environments a healthier start in life increased odds of term SGA. Air pollutant associations were robust to adjustment for road traffic noise. Trends of decreasing birth weight across increasing road traffic noise categories were observed, but were strongly attenuated when adjusted for primary traffic related air pollutants. Only $\mathrm{PM}_{2.5 \text { traffic exhaust }}$ and $\mathrm{PM}_{2.5}$ were consistently associated with increased risk of term LBW after adjustment for each of the other air pollutants. It was estimated that $3 \%$ of term LBW cases in London are directly attributable to residential exposure to $\mathrm{PM}_{2.5}>13.8 \mu \mathrm{g} / \mathrm{m}^{3}$ during pregnancy.

\section{CONCLUSIONS}

The findings suggest that air pollution from road traffic in London is adversely affecting fetal growth. The results suggest little evidence for an independent exposure-response effect of traffic related noise on birth weight outcomes.

\section{Introduction}

Air pollution is a major public health issue. It has been associated with reduced fetal growth, ${ }^{1}$ through which it may have extensive and permanent influences on thelife course. ${ }^{2}$ A key contributor to urban ambient pollution is road traffic and, critically, vehicle emissions are released near people. Urban particulate matter includes a large contribution from outside the urban area, and locally emitted particles. Close to roads an individual would be exposed to more primary exhaust and nonexhaust (brake or tyre wear and resuspension of road dust induced by vehicles) particles. Further away from roads an individual would be exposed to more nitrate and secondary organic aerosol as a proportion of their total particulate dose.

Road traffic also produces noise, which has been associated with adverse health outcomes such as hypertension and cardiovascular disease. ${ }^{3}$ Research on how noise affects birth outcomes is more limited, but a possible effect on LBW has been suggested. ${ }^{4}$ Noise could potentially influence fetal growth through stress, hypertension, and sleep disturbance. ${ }^{4-6}$

Evidence about the relative roles of air and noise pollution on birth weight is limited and inconsistent. ${ }^{7-9}$ To address health impacts of traffic effectively these need to be better understood. In this study, we investigate long-term exposure to both traffic related air and noise pollution during pregnancy in relation to birth weight outcomes.

\section{Methods}

\section{Births data}

The study boundary was the M25, an orbital motorway encompassing all of Greater London and parts of 


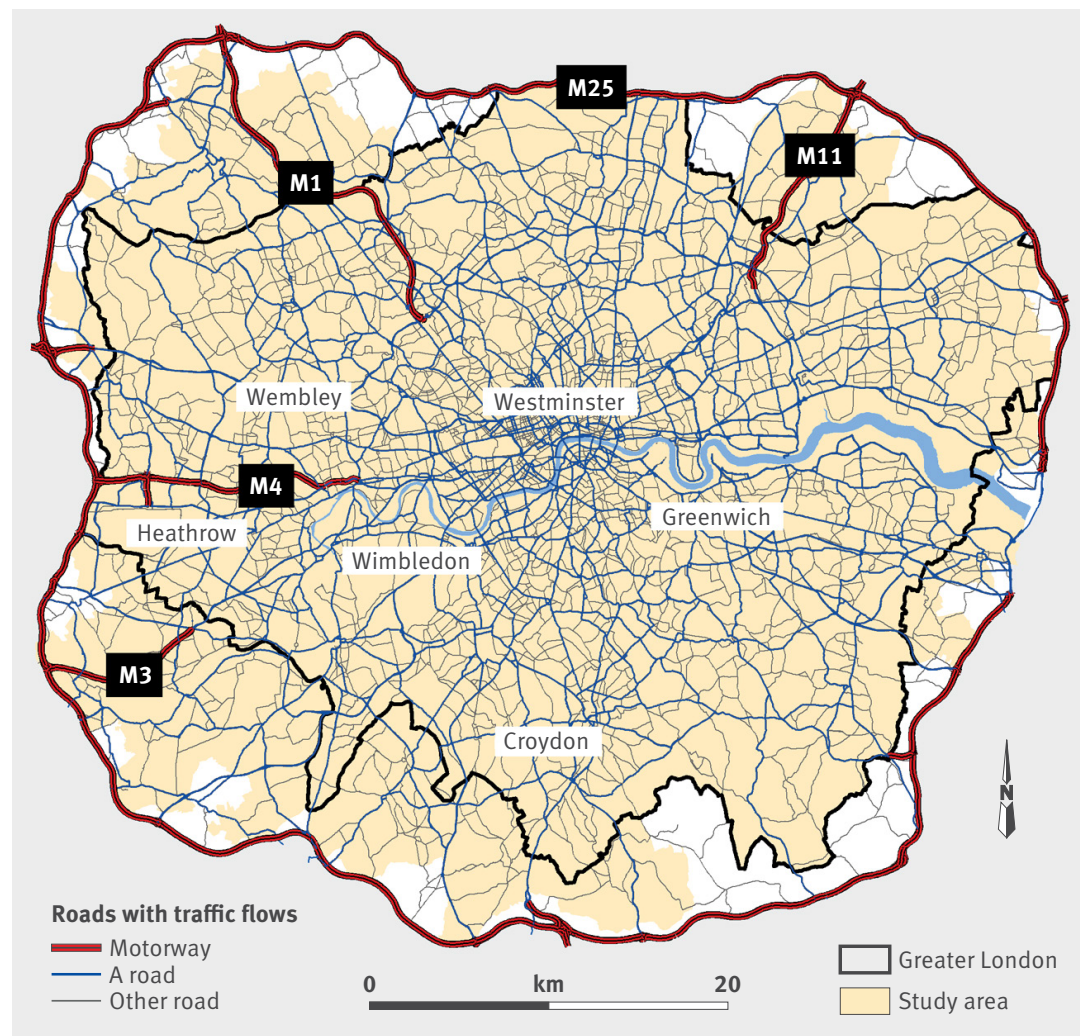

Fig 1 | Map of study area

\section{Air pollution exposures}

Average monthly concentrations of nitrogen dioxide $\left(\mathrm{NO}_{2}\right)$, nitrogen oxides $\left(\mathrm{NO}_{\mathrm{x}}\right)$, ozone $\left(\mathrm{O}_{3}\right)$, particulate matter with diameter $<2.5 \mu \mathrm{m}\left(\mathrm{PM}_{2.5}\right)$, particulate matter with diameter $<10 \mu \mathrm{m}\left(\mathrm{PM}_{10}\right), \mathrm{PM}_{2.5}$ from traffic exhaust $\left(\mathrm{PM}_{2.5 \text { traffic exhaust }}\right)$, and $\mathrm{PM}_{2.5}$ from traffic nonexhaust $\left(\mathrm{PM}_{2.5}\right.$ traffic non-exhaust $)$ were estimated for points on a $20 \mathrm{~m} \times 20 \mathrm{~m}$ regular grid across the study area, using dispersion modelling (KCLurban). ${ }^{12} \mathrm{NO}_{2}, \mathrm{NO}_{\mathrm{x}}, \mathrm{PM}_{2.5}$ traffic exhaust , and $\mathrm{PM}_{2.5}$ traffic non-exhaust are primary pollutants related to traffic (ie, locally emitted or rapidly formed near source oxidation products, or both). $\mathrm{PM}_{2.5}$ and $\mathrm{PM}_{10}$ are dominated by regional particles, long range particles, and secondary particles formed through atmospheric chemical reactions but also include particles from primary traffic sources. $\mathrm{O}_{3}$ is a regional, secondary pollutant. $\mathrm{PM}_{2.5}, \mathrm{PM}_{10}$, and $\mathrm{O}_{3}$ are more homogeneously distributed than primary pollutants related to traffic.

The KCLurban model uses Atmospheric Dispersion Modelling System (version 4) and road source model (version 2.3); data on emissions from the London Atmospheric Emissions Inventory (LAEI); ${ }^{13}$ empirically derived $\mathrm{NO}-\mathrm{NO}_{2}-\mathrm{O}_{3}$ and $\mathrm{PM}$ relations; and hourly meteorological information. ${ }^{12}$ The model performed well when evaluated against measurements, with high spearman correlation coefficients $(\rho)$ between observed versus modelled monthly concentrations: $\rho>0.91$ for $\mathrm{NO}_{\mathrm{x}}, \mathrm{PM}_{10}$, and $\mathrm{PM}_{2.5} ; \rho>0.83$ for $\mathrm{NO}_{2}$; and $\rho>0.9$ for $\mathrm{O}_{3}$ at both roadside and background locations. ${ }^{14}$ Normalised mean bias (NMB) and root mean square error (RMSE) for modelled monthly predictions were slightly higher for $\mathrm{NO}_{\mathrm{x}}$ (NMB 11\%; RMSE $13 \mu \mathrm{g} / \mathrm{m}^{3}$, $22 \%)$ and $\mathrm{NO}_{2}\left(11 \% ; 5.2 \mu \mathrm{g} / \mathrm{m}^{3}, 20 \%\right)$ compared with $\mathrm{PM}_{2.5}\left(5 \% ; 2.2 \mu \mathrm{g} / \mathrm{m}^{3}, 14 \%\right)$ and $\mathrm{PM}_{10}(6 \% ; 3.1 \mu \mathrm{g} /$ $\left.\mathrm{m}^{3}, 12 \%\right)$, indicating that whilst all have a positive bias (NMB), $\mathrm{PM}_{2.5}$ and $\mathrm{PM}_{10}$ are more accurately predicted than $\mathrm{NO}_{2}$ and $\mathrm{NO}_{x}$ (RMSE). Further detail about the modelling procedure and model evaluation is available elsewhere. ${ }^{12}{ }^{14}$ Using a Geographic Information System, each maternal residential address was assigned monthly air pollutant concentrations for the nearest $20 \mathrm{~m} \times 20 \mathrm{~m}$ grid point according to its geocoded XY coordinates. For each birth record, we calculated the time weighted average concentrations for $\mathrm{NO}_{\mathrm{x}}, \mathrm{NO}_{2}, \mathrm{PM}_{2.5 \text { traffic exhaus, }}, \mathrm{PM}_{2.5 \text { traffic non-exhaus, }}, \mathrm{PM}_{2.5}$, $\mathrm{PM}_{10}$, and $\mathrm{O}_{3}$ across pregnancy and for each trimester (first trimester defined as days 1-93, second as days 94186, and third as day 187 to day preceding delivery). The time weighting was based on the proportion of the pregnancy or trimester in each calendar month. ${ }^{15}$ ${ }^{16}$ To define trimesters, gestation period (available as completed weeks of pregnancy) was converted to days, and 4 days (rounded up from the midpoint 3.5 days) was added to adjust for potential underestimation where true gestation period was not an exact number of completed weeks.

\section{Road traffic noise exposures}

A-weighted road traffic noise levels $(\mathrm{dB})$ were modelled to $0.1 \mathrm{~dB}$ resolution for all geocoded maternal 
residential addresses using the Traffic Noise Exposure (TRANEX) model: ${ }^{17} \mathrm{~L}_{\text {Aeq,16hr }}$ (average sound level 07002300 hours); $\mathrm{L}_{\text {night }}$ (2300-0700); $\mathrm{L}_{\text {day }}$ (0700-1900); $\mathrm{L}_{\text {eve }}$ (1900-2300); $\mathrm{L}_{\text {den }}$ (logarithmic composite of $\mathrm{L}_{\text {day }}, \mathrm{L}_{\text {eve }}$, and $\mathrm{L}_{\text {night }}$ with $5 \mathrm{~dB}$ added to the $\mathrm{L}_{\text {eve }}$ and $10 \mathrm{~dB}$ added to $\mathrm{L}_{\text {night }}$ ). Model validation studies conducted in two UK cities showed high Spearman's correlation $(\rho=0.90)$ between measured and modelled noise levels, indicating good model performance. ${ }^{17}$ The geocoded address points are for the geometric centroid of the dwelling, so for the purposes of noise modelling, the address points were universally moved to one metre from the façade on the side of the dwelling closest to the nearest road section with traffic information, as described elsewhere. ${ }^{17}$ We modelled noise for one midpoint year (2007) and applied these values to other years for the same address locations because temporal variability in noise over the study period was negligible. Noise could not be estimated for $4.5 \%$ of births owing to maternal residential address point (receptor) placement issues, ${ }^{17}$ however, these addresses were randomly distributed across the study area. We flagged addresses exposed to A-weighted $\mathrm{L}_{\text {day }}>50 \mathrm{~dB}$ from railways or aircraft (Heathrow Airport and London City Airport). Railway and London City Airport noise data were from Environmental Noise Directive strategic noise mapping (2006 annual average), and Heathrow Airport noise data were from annual average contours (2001) from the Civil Aviation Authority.

\section{Outcomes}

Term low birth weight (LBW) was defined as birth weight less than $2500 \mathrm{~g}$ and gestational age of 37 weeks or more. ${ }^{18}$ SGA was defined as birth weight for gestational age less than the 10th centile by sex and ethnicity (to account for constitutional differences in birth weight by sex and ethnic group, and thus better identify pathologically small infants).

We initially excluded births with gestational age less than 24 or greater than 44 weeks $(n=1083$, $0.2 \%)$, missing or implausible $(<200 \mathrm{~g}$ or $>9000 \mathrm{~g})$ birth weight $(n=5747,0.9 \%)$, and missing gestational age $(n=9725,1.5 \%)$. Birth weight outliers were then identified and excluded according to Tukey's rule (ie, values greater than twice the interquartile range (IQR), below the first quartile, and above the third quartile for each gestational week) both overall and separately according to sex and ethnicity (white, Asian, black, or other) for the calculation of sex-ethnicity specific birth weight for gestational age centiles. ${ }^{19}$ Stillbirths were retained at this stage, because excluding stillbirths overestimates centiles for gestation $<28$ weeks by up to $30 \%{ }^{20}$ We identified $0.58 \%$ of the observations overall as outliers. We calculated smoothed sex-ethnicity specific birth weight for gestational age centile curves according to the LMS method using LMSChartMaker Light V.2.54 software which has been used in previous research. ${ }^{21-26}$ The software can hold a maximum of 100000 records, so a subsample of 100000 was randomly selected if the number of records for a given sex and ethnicity subgroup exceeded this.
Representativeness of these 100000 samples for their particular subgroup with respect to exposures or potential confounders was checked and confirmed. We did not calculate centiles or SGA for the ethnic group 'other', as it does not represent a meaningful homogeneous ethnic group for analysis.

We excluded birth weight outliers $(n=3815,0.6 \%)$, stillbirths (3910, 0.6\%), preterm births (40346, $6.1 \%)$, births missing noise exposure $(31197,4.7 \%)$, and births missing ethnicity (47710, 7.2\%), leaving 540365 singleton term live births eligible for birth weight analyses, and 471489 for SGA analyses (the exclusions were not mutually exclusive).

\section{Statistical Methods}

Air pollutant exposures were analysed as continuous measures, rescaled to both IQR increments and increments specific to pollutants $\left(\mathrm{NO}_{2}, 10 \mu \mathrm{g} / \mathrm{m}^{3}\right.$; $\mathrm{NO}_{\mathrm{x}}$, $20 \mu \mathrm{g} / \mathrm{m}^{3} ; \mathrm{PM}_{2.5 \text { traffic exhaust }}, 1 \mu \mathrm{g} / \mathrm{m}^{3} ; \mathrm{PM}_{2.5}$ traffic non-exhaust, $1 \mu \mathrm{g} / \mathrm{m}^{3} ; \mathrm{PM}_{2.5}, 5 \mu \mathrm{g} / \mathrm{m}^{3} ; \mathrm{PM}_{10}, 10 \mu \mathrm{g} / \mathrm{m}^{3} ; \mathrm{O}_{3}, 10 \mu \mathrm{g} /$ $\mathrm{m}^{3}$ ). Where multiple air pollutants are examined it is a common approach to rescale to the IQR, in order to calculate effect estimates for comparable increases across the different pollutants (which may have very different absolute concentration ranges). The IQR is the difference between the 75 th and 25th centiles of the distribution. As all noise metrics were highly correlated ( $\rho \geq 0.997)$, we limited analysis to one daytime $\left(\mathrm{L}_{\text {Aeq, 16hr }}\right)$ and one night-time $\left(\mathrm{L}_{\text {night }}\right)$ metric. Noise metrics were right skewed, so were categorised $\left(\mathrm{L}_{\text {Aeq,16hr }}<55 \mathrm{~dB}\right.$ (reference), 55 to $<60 \mathrm{~dB}, 60$ to $<65 \mathrm{~dB}$, and $\geq 65 \mathrm{~dB}$; and $\mathrm{L}_{\text {night }}<50 \mathrm{~dB}$ (reference), 50 to $<55 \mathrm{~dB}, 55$ to $<60$ $\mathrm{dB}, 60$ to $<65 \mathrm{~dB}$, and $\geq 65 \mathrm{~dB}$ ) for primary analysis. We examined the functional relation between term birth weight and noise (supplementary figure 1 in web appendix 1) using generalised additive models, and there were no major departures from linearity so we additionally analysed noise as a continuous variable, rescaled to IQR increment.

We analysed continuous birth weight using linear regression, and LBW or SGA using logistic regression. We limited analyses to term births. We adjusted all models for maternal age $(<25,25-29,30-34$, or $\geq 35$ years); birth registration type (within marriage, sole registration, joint with same address, joint with different address); birth season; birth year; Carstairs deprivation quintile; tobacco expenditure (continuous); and a random intercept for middle layer super output areas. Birth weight and LBW were also adjusted for sex, gestational age (linear and quadratic terms), and baby's ethnicity (white, Asian, black, other). All covariates were included in the model a priori based on previous knowledge, except for birth season, birth year, and the random intercept for middle layer super output areas which were included as they were influential in the model. In joint air pollutant-noise models we further adjusted air pollutants for noise, and vice versa. We ran two air pollutant models for term LBW and continuous term birth weight, assessing models on a case by case basis for collinearity by inspecting the variance inflation 


$$
\sum_{i=0}^{k} p d_{i}\left(\frac{R R_{i}-1}{R R_{i}}\right)
$$

Fig 2 | Equation. $\mathrm{pd}_{\mathrm{i}}=$ the proportion of cases falling into ith exposure level; $R_{\mathrm{i}}=$ the adjusted relative risk comparing ith exposure level with reference group $(i=0)$

factor and standard errors. We also evaluated the relation between exposures and term birth weight (unadjusted, adjusted, and joint exposure models) using generalised additive models to evaluate nonlinearity.

We ran sensitivity analyses on joint air pollutantnoise models evaluating possible effect modification by ethnicity (interaction term for exposure multiplied by ethnicity); and excluding those exposed to aircraft or railway noise $>50 \mathrm{~dB}$ - the latter to remove the influence of high aircraft or railway noise and allow the evaluation of the influence of road traffic noise in a cleaner subgroup.

\begin{tabular}{|c|c|c|c|c|c|c|c|c|c|c|c|c|c|}
\hline \multirow[b]{2}{*}{ Variable } & \multirow[b]{2}{*}{ No } & \multirow[b]{2}{*}{$\begin{array}{l}\text { Mean term } \\
\text { birth } \\
\text { weight (g) }\end{array}$} & \multirow[b]{2}{*}{$\begin{array}{l}\text { Term } \\
\text { LBW } \\
(\%)\end{array}$} & \multirow[b]{2}{*}{$\begin{array}{l}\text { Term } \\
\text { SGA* } \\
(\%)\end{array}$} & \multicolumn{7}{|c|}{ Mean pregnancy average concentration $\left(\mu \mathrm{g} / \mathrm{m}^{3}\right)$} & \multicolumn{2}{|c|}{$\%$ Exposed $\geq 65 \mathrm{~dB}$} \\
\hline & & & & & $\mathrm{NO}_{2}$ & $\mathrm{NO}_{\mathrm{x}}$ & $\begin{array}{l}\mathrm{PM}_{2.5} \\
\text { traffic } \\
\text { exhaust }\end{array}$ & $\begin{array}{l}\mathrm{PM}_{2.5} \\
\text { traffic } \\
\text { non-exhaust }\end{array}$ & $\mathrm{PM}_{2.5}$ & $\mathrm{PM}_{10}$ & $\mathrm{O}_{3}$ & $\mathrm{LA}_{\mathrm{eq}, 16 \mathrm{hr}}$ & $\mathrm{L}_{\text {night }}$ \\
\hline Total population & 540365 & 3392 & 2.6 & 9.5 & 40.6 & 72.5 & 0.61 & 0.73 & 14.4 & 23.1 & 31.9 & 14.2 & 6.3 \\
\hline \multicolumn{14}{|l|}{ Infant sex: } \\
\hline Male & 275546 & 3454 & 2.1 & 9.5 & 40.6 & 72.5 & 0.61 & 0.73 & 14.4 & 23.1 & 31.9 & 14.1 & 6.2 \\
\hline Female & 264819 & 3328 & 3.1 & 9.5 & 40.6 & 72.4 & 0.61 & 0.73 & 14.4 & 23.1 & 31.9 & 14.2 & 6.3 \\
\hline \multicolumn{14}{|l|}{ Maternal age (years): } \\
\hline$<25$ & 100931 & 3316 & 3.3 & 12.7 & 40.8 & 73.0 & 0.62 & 0.73 & 14.5 & 23.2 & 31.7 & 15.9 & 7.1 \\
\hline $25-29$ & 140353 & 3369 & 2.8 & 9.7 & 40.5 & 72.3 & 0.61 & 0.73 & 14.4 & 23.1 & 31.9 & 15.3 & 6.9 \\
\hline $30-34$ & 169559 & 3421 & 2.2 & 8.6 & 40.4 & 72.1 & 0.61 & 0.72 & 14.4 & 23.0 & 32.0 & 13.6 & 6.0 \\
\hline$\geq 35$ & 129522 & 3438 & 2.2 & 8.2 & 40.6 & 72.7 & 0.61 & 0.72 & 14.4 & 23.1 & 31.8 & 12.3 & 5.2 \\
\hline \multicolumn{14}{|l|}{ Ethnicity: } \\
\hline White & 286192 & 3470 & 1.7 & 9.6 & 39.8 & 70.5 & 0.59 & 0.70 & 14.3 & 22.9 & 32.3 & 12.9 & 5.5 \\
\hline Asian & 93555 & 3196 & 5.1 & 9.6 & 40.9 & 73.1 & 0.62 & 0.74 & 14.4 & 23.1 & 31.7 & 15.0 & 6.4 \\
\hline Black & 91740 & 3359 & 2.8 & 9.4 & 42.0 & 76.2 & 0.66 & 0.78 & 14.6 & 23.5 & 31.0 & 15.4 & 7.2 \\
\hline Other & 68878 & 3379 & 2.3 & & 41.4 & 74.6 & 0.64 & 0.76 & 14.5 & 23.3 & 31.5 & 16.6 & 7.8 \\
\hline \multicolumn{14}{|l|}{ Birth registration: } \\
\hline Within marriaget & 348157 & 3397 & 2.5 & 13.0 & 40.6 & 72.6 & 0.61 & 0.73 & 14.4 & 23.1 & 31.8 & 13.7 & 6.0 \\
\hline Sole registration & 35937 & 3329 & 3.4 & 10.3 & 41.3 & 74.4 & 0.64 & 0.75 & 14.6 & 23.3 & 31.4 & 15.7 & 7.4 \\
\hline $\begin{array}{l}\text { Joint with same } \\
\text { address }\end{array}$ & 105239 & 3425 & 2.2 & 12.9 & 40.0 & 70.9 & 0.60 & 0.71 & 14.4 & 23.0 & 32.3 & 14.8 & 6.7 \\
\hline $\begin{array}{l}\text { Joint with different } \\
\text { address }\end{array}$ & 51032 & 3339 & 3.2 & 9.5 & 40.8 & 73.1 & 0.62 & 0.74 & 14.4 & 23.1 & 31.7 & 14.6 & 6.5 \\
\hline \multicolumn{14}{|l|}{ Birth season: } \\
\hline Winter & 130033 & 3382 & 2.7 & 9.7 & 39.6 & 70.1 & 0.61 & 0.71 & 13.9 & 22.6 & 31.0 & 14.4 & 6.4 \\
\hline Spring & 133395 & 3390 & 2.6 & 9.4 & 43.3 & 79.6 & 0.68 & 0.78 & 14.8 & 23.8 & 27.4 & 13.9 & 6.0 \\
\hline Summer & 138418 & 3399 & 2.5 & 9.3 & 42.0 & 76.2 & 0.63 & 0.75 & 15.0 & 23.8 & 32.8 & 14.1 & 6.3 \\
\hline Autumn & 138519 & 3398 & 2.5 & 9.5 & 37.4 & 64.0 & $z$ & 0.66 & 13.9 & 22.3 & 36.1 & 14.3 & 6.4 \\
\hline \multicolumn{14}{|l|}{ Birth year: } \\
\hline 2006 & 101770 & 3382 & 2.8 & 9.7 & 42.3 & 77.6 & 0.72 & 0.71 & 16.1 & 25.1 & 30.4 & 13.7 & 6.0 \\
\hline 2007 & 106528 & 3388 & 2.6 & 9.4 & 40.6 & 71.7 & 0.63 & 0.69 & 14.8 & 24.1 & 34.2 & 13.9 & 6.1 \\
\hline 2008 & 106678 & 3394 & 2.6 & 9.3 & 42.1 & 77.7 & 0.63 & 0.76 & 14.5 & 23.5 & 30.6 & 14.1 & 6.2 \\
\hline 2009 & 110014 & 3397 & 2.5 & 9.1 & 41.0 & 73.1 & 0.60 & 0.77 & 14.0 & 22.6 & 27.4 & 14.2 & 6.3 \\
\hline 2010 & 115375 & 3398 & 2.4 & 9.5 & 37.3 & 63.2 & 0.51 & 0.69 & 12.9 & 20.5 & 36.5 & 14.8 & 6.6 \\
\hline \multicolumn{14}{|l|}{ Carstairs quintile: } \\
\hline 1st, least deprived & 85358 & 3467 & 1.6 & 8.9 & 37.3 & 64.2 & 0.51 & 0.61 & 14.1 & 22.5 & 33.7 & 9.2 & 2.6 \\
\hline 2nd & 92264 & 3433 & 2.0 & 9.4 & 39.3 & 69.3 & 0.57 & 0.69 & 14.3 & 22.8 & 32.6 & 13.6 & 5.6 \\
\hline $3 r d$ & 100934 & 3400 & 2.4 & 10.1 & 40.4 & 72.0 & 0.60 & 0.72 & 14.4 & 23.0 & 32.0 & 15.2 & 6.6 \\
\hline 4th & 119239 & 3368 & 2.9 & 10.7 & 41.1 & 73.8 & 0.63 & 0.75 & 14.5 & 23.2 & 31.5 & 15.9 & 7.2 \\
\hline 5th, most deprived & 142570 & 3335 & 3.3 & 9.5 & 43.0 & 78.6 & 0.70 & 0.81 & 14.7 & 23.6 & 30.5 & 15.3 & 7.9 \\
\hline \multicolumn{14}{|c|}{ Tobacco expenditure quintile: } \\
\hline $1 \mathrm{st}$ & 110332 & 3436 & 1.9 & 8.3 & 37.9 & 65.7 & 0.52 & 0.63 & 14.2 & 22.6 & 33.3 & 10.5 & 3.2 \\
\hline 2nd & 110146 & 3415 & 2.3 & 9.0 & 40.1 & 71.3 & 0.59 & 0.71 & 14.4 & 23.0 & 32.1 & 13.5 & 5.5 \\
\hline $3 r d$ & 109477 & 3389 & 2.6 & 9.6 & 41.0 & 73.6 & 0.63 & 0.75 & 14.5 & 23.2 & 31.6 & 16.2 & 7.6 \\
\hline 4th & 109499 & 3362 & 3.0 & 10.3 & 41.0 & 73.5 & 0.63 & 0.74 & 14.5 & 23.2 & 31.7 & 16.2 & 7.8 \\
\hline 5th & 100911 & 3354 & 3.1 & 10.7 & 42.9 & 78.6 & 0.70 & 0.80 & 14.7 & 23.6 & 30.6 & 14.5 & 7.4 \\
\hline \multicolumn{14}{|l|}{ London region: } \\
\hline Inner & 173181 & 3395 & 2.5 & 9.4 & 45.1 & 84.3 & 0.78 & 0.88 & 14.8 & 24.0 & 29.4 & 17.1 & 9.4 \\
\hline Outer & 367184 & 3391 & 2.6 & 9.5 & 38.4 & 66.9 & 0.54 & 0.65 & 14.2 & 22.7 & 33.1 & 12.8 & 4.8 \\
\hline
\end{tabular}

LBW=low birth weight ( $<2500 \mathrm{~g})$; SGA=small for gestational age

*SGA, \% out of a total 471489 for whom sex-ethnicity specific SGA calculated

tIncludes civil partnerships 


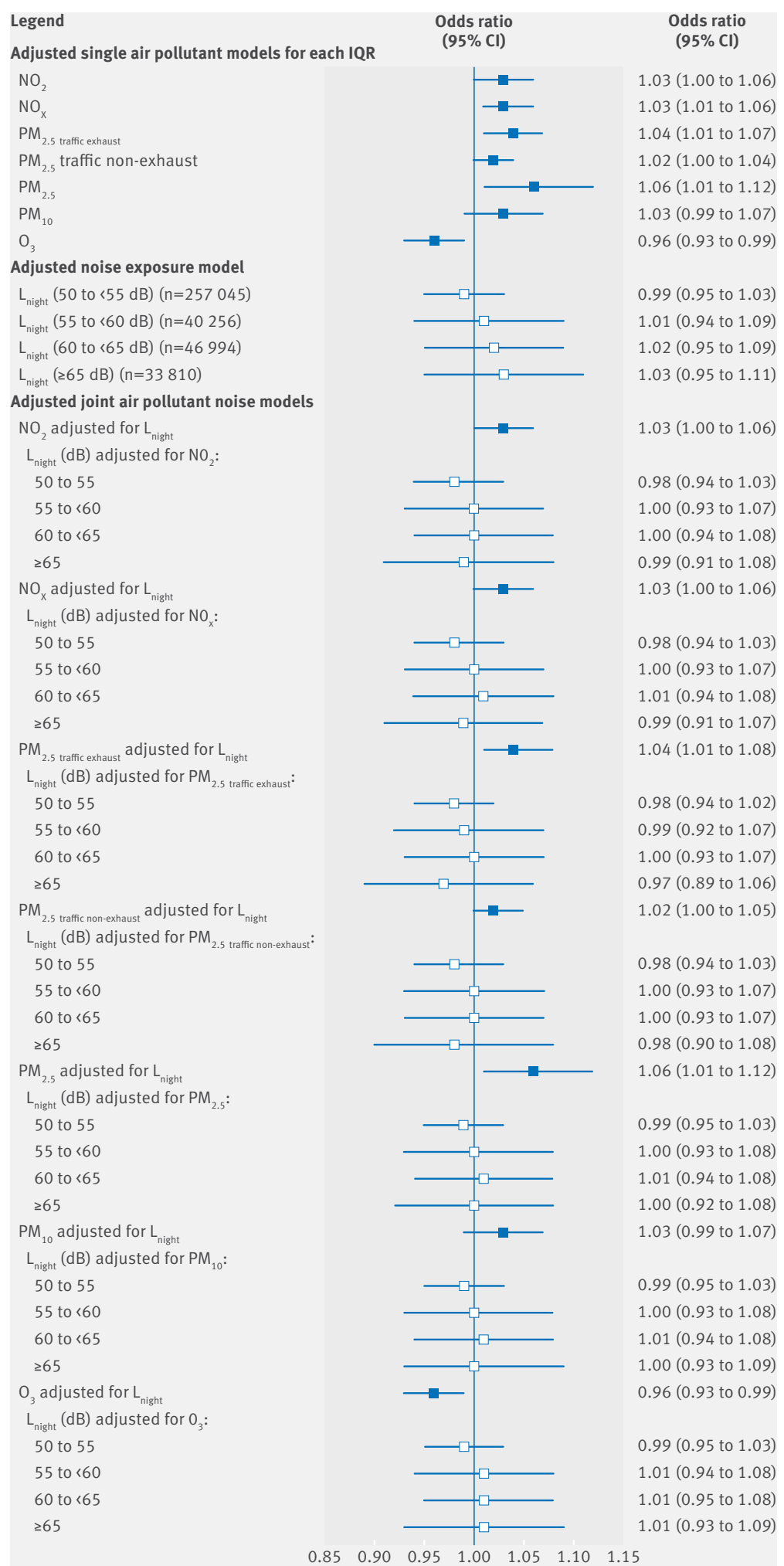

Fig 3 | Odds of term low birth weight (LBW) associated with air pollutants (for each interquartile range $(I Q R))$ and night-time noise $\left(\mathrm{L}_{\text {nigh }}\right)$ in single exposure and joint exposure models. Odds ratios for night-time noise $\left(\mathrm{L}_{\text {night }}\right)$ are versus the reference group $<50 \mathrm{~dB}$. All models are adjusted for sex, maternal age, ethnicity, birth registration type, birth season, birth year, Carstairs quintile (census output area level), tobacco expenditure (census output area level), gestational age as linear and quadratic terms, and random intercept for middle layer super output areas, in addition to including the air pollutant or noise metrics shown above. IQR values for air pollutants: $\mathrm{NO}_{2}$ (for each IQR, 8.6 $\left.\mu \mathrm{g} / \mathrm{m}^{3}\right), \mathrm{NO}_{\mathrm{x}}\left(23.7 \mu \mathrm{g} / \mathrm{m}^{3}\right), \mathrm{PM}_{2.5}$ traffic exhaust $\left(0.35 \mu \mathrm{g} / \mathrm{m}^{3}\right), \mathrm{PM}_{2.5 \text { traffic non-exhaust }}(0.29$ $\left.\mu \mathrm{g} / \mathrm{m}^{3}\right), \mathrm{PM}_{2.5}\left(2.2 \mu \mathrm{g} / \mathrm{m}^{3}\right), \mathrm{PM}_{10}\left(3.0 \mu \mathrm{g} / \mathrm{m}^{3}\right)$, and $\mathrm{O}_{3}\left(8.4 \mu \mathrm{g} / \mathrm{m}^{3}\right)$
We calculated the population attributable fraction for term LBW for exposure to $\mathrm{PM}_{2.5}$ greater than the 25 th centile of the exposure distribution, using the formula in figure $2 .{ }^{27}$ The exposure levels were quartiles for this calculation. All analyses were conducted in Stata (version 13), except generalised additive models which were run in $\mathrm{R}$ (version 3.1.2) using the mgcv package. No adjustment for multiple testing was made.

\section{Patient involvement}

No patients were involved in setting the research question or the outcome measures, nor were they involved in developing plans for design or implementation of the study. No patients were asked to advise on interpretation or writing up of results. There are no plans to disseminate the results of the research to study participants or the relevant patient community.

\section{Results}

Table 1 shows that $2.6 \%$ and $9.5 \%$ of term births were classified as LBW and SGA respectively. Over the study period of 2006 to 2010, there were temporal trends for LBW (decreasing), air pollutant exposures (decreasing particularly for $\mathrm{PM}_{2.5}$ traffic-exhaust, $\mathrm{PM}_{2.5}$, $\mathrm{PM}_{10}$ ), and an increasing proportion of births with high noise exposures, the latter reflecting change in spatial distribution of maternal addresses over time, as noise modelling was not time varying. Supplementary table 1 in web appendix 1 shows that air pollutant exposures were positively correlated (0.45 to 1.00), except with $\mathrm{O}_{3}(-0.46$ to -0.77$)$. Daytime and night-time road traffic noise were very highly correlated $(\sim 1.00)$, and road traffic noise was positively correlated with air pollutant exposures (0.15 to 0.50) except $\mathrm{O}_{3}(\sim-0.15)$. Maternal age, ethnicity, birth registration type, birth season, birth year, deprivation (Carstairs quintile), and tobacco expenditure were associated with outcomes and exposures (supplementary tables 2 and 3 in web appendix 1).

\section{Air pollution}

Figure 3 and supplementary tables 4 to 6 in web appendix 1 show that in single pollutant adjusted models, IQR increases in exposure to primary pollutants related to traffic $\left(\mathrm{NO}_{2}, \mathrm{NO}_{\mathrm{x}}, \mathrm{PM}_{2.5}\right.$ traffic exhaust, $\left.\mathrm{PM}_{2.5 \text { traffic non-exhaust }}\right), \mathrm{PM}_{2.5}$, and $\mathrm{PM}_{10}$ during pregnancy were associated with $2 \%$ to $6 \%$ increased odds of term LBW (eg, odds ratios of 1.03, 95\% confidence interval 1.00 to 1.06 for $\mathrm{NO}_{2}$; and $1.04,1.01$ to 1.07 for $\mathrm{PM}_{2.5 \text { traffic exhaust }}$ ), $1 \%$ to $3 \%$ increased odds of term SGA, and reduced term birth weight. Figure 3 shows that decreased odds of term LBW were observed with increasing $\mathrm{O}_{3}$ exposure. Consistent with this, in adjusted generalised additive models, term birth weight decreased approximately linearly with increasing exposure to air pollutants (except $\mathrm{O}_{3}$ ) (not shown).

Figure 4 shows that in two air pollutant models, only $\mathrm{PM}_{2.5}$ traffic exhaust and $\mathrm{PM}_{2.5}$ consistently had odds ratios above one associated with term LBW when adjusted, 


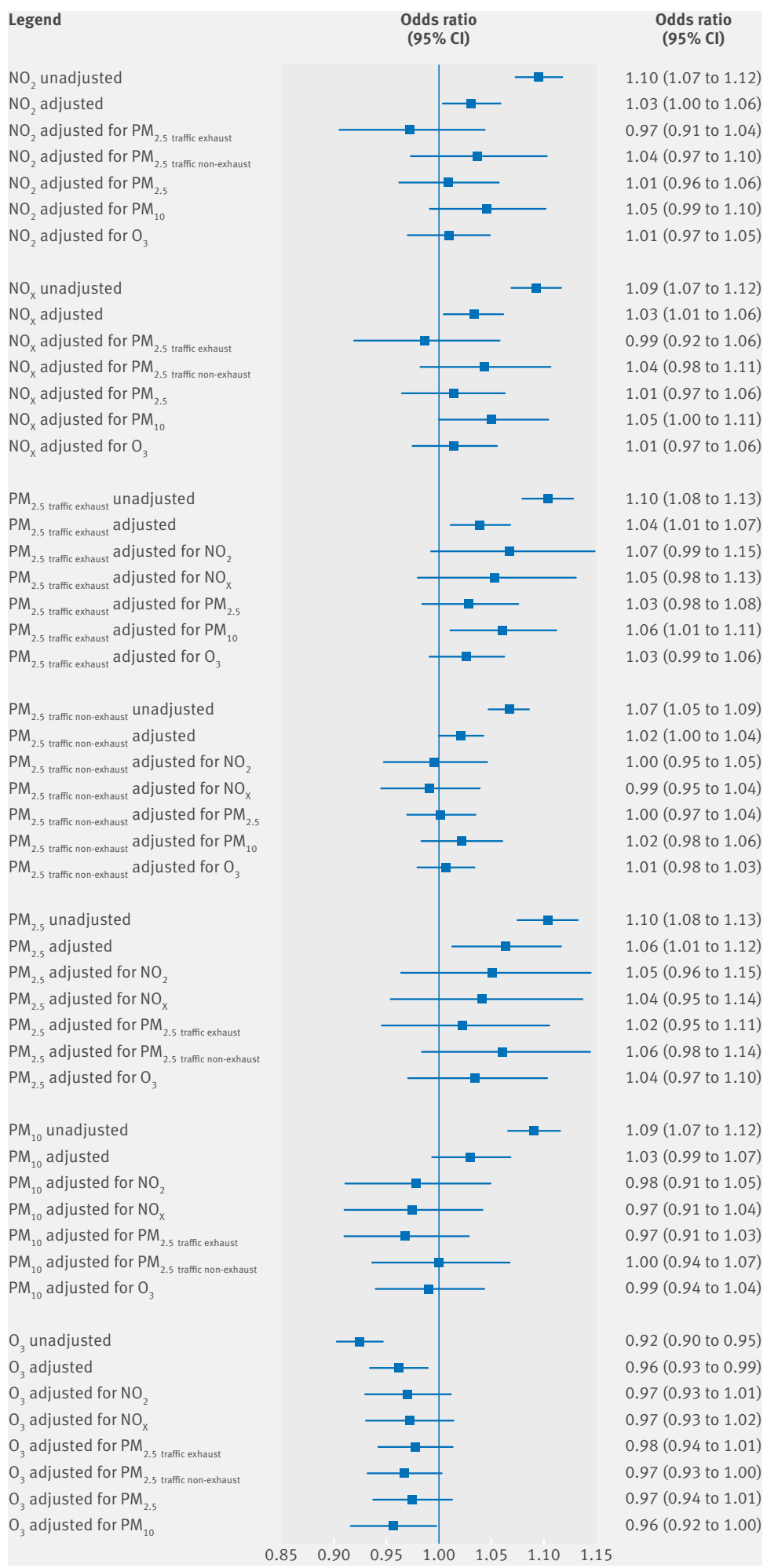

Fig 4 | Odds of term low birth weight (LBW), associated with interquartile range (IQR) increases in air pollutants, in single and two air pollutant models. Adjusted models are adjusted for sex, maternal age, ethnicity, birth registration type, birth season, birth year, Carstairs quintile (census output area level), tobacco expenditure (census output area (evel), gestational age as linear and quadratic terms, and random intercept for middle layer super output areas, in addition to including the air pollutant shown above. $\mathrm{NO}_{2}$ and $\mathrm{NO}_{\mathrm{x}}$ were not entered into the same model together as they were too highly correlated. $\mathrm{PM}_{2.5}$ and $\mathrm{PM}_{10}$ were not entered into the same model together as $\mathrm{PM}_{2.5}$ is a substantial subset of $\mathrm{PM}_{10}$ ( $>50 \%$ by mass). IQR values for air pollutants: $\mathrm{NO}_{2}$ (for each $\left.\mathrm{IQR}, 8.6 \mu \mathrm{g} / \mathrm{m}^{3}\right), \mathrm{NO}_{\mathrm{x}}\left(23.7 \mu \mathrm{g} / \mathrm{m}^{3}\right), \mathrm{PM}_{2.5 \text { traffic exhaust }}\left(0.35 \mu \mathrm{g} / \mathrm{m}^{3}\right), \mathrm{PM}_{2.5 \text { traffic non-exhaust }}(0.29$ $\left.\mu \mathrm{g} / \mathrm{m}^{3}\right), \mathrm{PM}_{2.5}\left(2.2 \mu \mathrm{g} / \mathrm{m}^{3}\right), \mathrm{PM}_{10}\left(3.0 \mu \mathrm{g} / \mathrm{m}^{3}\right)$, and $\mathrm{O}_{3}\left(8.4 \mu \mathrm{g} / \mathrm{m}^{3}\right)$ in turn, for other air pollutants. Reduced term birth weight was consistently associated with $\mathrm{PM}_{2.5}$ traffic-exhaust only (supplementary figure 2 in web appendix 1). We checked two air pollutant models for multicollinearity on a case by case basis. Models with very high variance inflation factors were excluded (eg, $\mathrm{PM}_{2.5}$ traffic exhaust and $\mathrm{PM}_{2.5 \text { traffic non-exhaust }}$ ), and where variance inflation factor values were borderline around 10, we excluded the model if the standard error more than doubled. However, for all two air pollutant models presented there was some increase in the standard errors for the exposure terms, which reflects the correlation structure between pollutants.

\section{Noise}

Figure 3 and supplementary tables 4 and 5 in web appendix 1 show that in adjusted models, high ( $\geq 65 \mathrm{~dB}$ ) night-time road traffic noise exposure was associated with an odds ratio of 1.03 (95\% confidence interval, 0.95 to 1.11) for term LBW, and 1.03 (0.99 to 1.08) for term SGA, compared with the reference group ( $<50 \mathrm{~dB})$, with a suggestion of increasing odds ratios across increasing night-time noise categories for term LBW. There was a suggestion of an exposure-response relation of decreasing term birth weight across increasing night-time and daytime road traffic noise categories (supplementary table 6 in web appendix 1). In adjusted generalised additive models, term birth weight decreased with increasing exposure to road traffic noise in a largely linear fashion (not shown).

\section{Air pollution and noise}

Figures 3 and 5 and table 2 show that air pollutant associations with term LBW were robust to adjustment for night-time or daytime road traffic noise, with virtually no change to odds ratios. The same holds for term SGA (table 2) and term birth weight (supplementary figures 3 and 4 and supplementary table 7 in web appendix 1). Air pollutant effect estimates adjusted for noise as a continuous variable (for each IQR) (supplementary table 8 in web appendix 1) were virtually identical to those from the primary analysis which adjusted for noise as a categorical variable. Consistent with the linear regression models, in adjusted joint exposure generalised additive models, air pollution associations with term birth weight were robust to adjustment for road traffic noise. Figure 6 shows the joint model for $\mathrm{NO}_{2}$ and night-time noise $\left(\mathrm{L}_{\text {night }}\right)$, with the remaining models in web appendix 1.

Models are adjusted for sex (term LBW model only), maternal age, ethnicity (term LBW model only), birth registration type, birth season, birth year, Carstairs quintile (census output area level), tobacco expenditure (census output area level), gestational age as linear and quadratic terms, and random intercept for middle layer super output areas, in addition to including the air pollutant or noise metrics shown above. All air pollution estimates are adjusted for either night-time $\left(\mathrm{L}_{\text {night }}\right)$ or daytime noise $\left(\mathrm{L}_{\text {Aeq 16hr }}\right)$ as specified in the table, and noise estimates are adjusted for traffic related air pollution exposure $\left(\mathrm{NO}_{2}\right)$. IQR values for air 


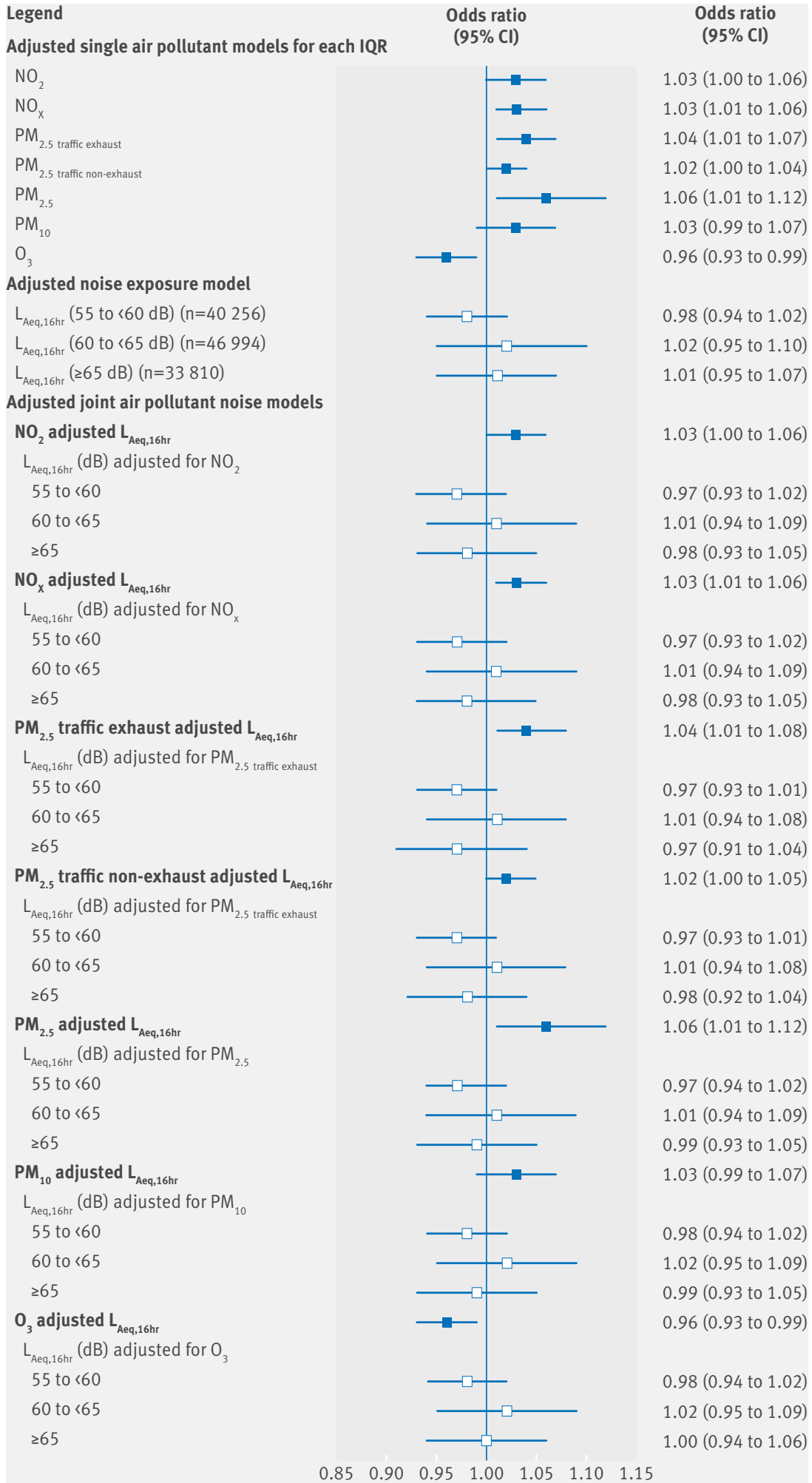

Fig 5 | Odds of term LBW associated with air pollutants (for each interquartile range $(\mathrm{IQR})$ ) and daytime noise $\left(\mathrm{L}_{\text {Aeq, 16hr }}\right)$, in single exposure and joint exposure models. All noise odds ratios are versus the reference group $<55 \mathrm{~dB}$. All models are adjusted for sex, maternal age, ethnicity, birth registration type, birth season, birth year, Carstairs quintile (census output area level), tobacco expenditure (census output area level), gestational age as linear and quadratic terms, and random intercept for middle layer super output areas, in addition to including the air pollutant or noise metrics shown above. IQR values for air pollutants: $\mathrm{NO}_{2}$ (for each IQR, $\left.8.6 \mu \mathrm{g} / \mathrm{m}^{3}\right), \mathrm{NO}_{\mathrm{x}}\left(23.7 \mu \mathrm{g} / \mathrm{m}^{3}\right.$ ), $\mathrm{PM}_{2.5 \text { traffic exhaust }}\left(0.35 \mu \mathrm{g} / \mathrm{m}^{3}\right), \mathrm{PM}_{2.5 \text { traffic non-exhaust }}\left(0.29 \mu \mathrm{g} / \mathrm{m}^{3}\right), \mathrm{PM}_{2.5}\left(2.2 \mu \mathrm{g} / \mathrm{m}^{3}\right), \mathrm{PM}_{10}$ $\left(3.0 \mu \mathrm{g} / \mathrm{m}^{3}\right)$, and $\mathrm{O}_{3}\left(8.4 \mu \mathrm{g} / \mathrm{m}^{3}\right)$ pollutants: $\mathrm{NO}_{2}$ (for each IQR, $\left.8.6 \mu \mathrm{g} / \mathrm{m}^{3}\right), \mathrm{NO}_{\mathrm{x}}(23.7$ $\left.\mu \mathrm{g} / \mathrm{m}^{3}\right), \mathrm{PM}_{2.5}$ trafficexhaust $\left(0.35 \mu \mathrm{g} / \mathrm{m}^{3}\right), \mathrm{PM}_{2.5 \text { traffic non-exhaust }}$ $\left(0.29 \mu \mathrm{g} / \mathrm{m}^{3}\right), \mathrm{PM}_{2.5}\left(2.2 \mu \mathrm{g} / \mathrm{m}^{3}\right), \mathrm{PM}_{10}\left(3.0 \mu \mathrm{g} / \mathrm{m}^{3}\right)$, and $\mathrm{O}_{3}\left(8.4 \mu \mathrm{g} / \mathrm{m}^{3}\right)$

After adjustment for each air pollutant, in turn, there was no evidence that increasing night-time or daytime road traffic noise exposure (analysed as either a categorical or continuous variable) was associated with increasing risk of term LBW (figs 3 and 5) or term SGA (supplementary tables 8 and 9 in web appendix 1). There was some suggestion of an association with reduced term birth weight in the highest night-time road traffic noise category after adjustment for $\mathrm{NO}_{2}$ or $\mathrm{NO}_{\mathrm{x}}$ but not after adjustment for $\mathrm{PM}_{2.5}$ traffic exhaust or $\mathrm{PM}_{2.5 \text { traffic non-exhaust }}$. However, this was not evident in adjusted joint exposure generalised additive models - which indicated that once adjusted for any of the primary traffic related air pollutants, in turn, there appears to be no relation between road traffic noise and term birth weight (fig 6 and web appendix 1). A weak association remained between road traffic noise and reduced term birth weight after adjustment for $\mathrm{PM}_{2.5}, \mathrm{PM}_{10}$, and $\mathrm{O}_{3}$ in linear regression (supplementary figure 3 and supplementary tables 8 and 9 in web appendix 1) and generalised additive models (web appendix 1).

\section{Trimester specific air pollution models}

For term LBW, odds ratios for primary traffic related air pollutant exposures in the second and third trimesters tended to be stronger than for first trimester exposures (supplementary table 10 in web appendix 1). Conversely, for term SGA, odds ratios for exposures in earlier trimesters were stronger than the third trimester exposure for $\mathrm{PM}_{2.5}$ traffic exhaust and $\mathrm{PM}_{2.5}$ traffic non-exhaust, and first trimester exposure appeared to be strongest for $\mathrm{PM}_{2.5}$ and $\mathrm{PM}_{10}$ (supplementary table 10 in web appendix 1). However, confidence intervals for trimester specific effects overlapped. These analyses are presented according to prespecified pollutant specific increments (not IQR) to allow comparison between trimesters for each pollutant.

\section{Additional analyses}

Compared with unadjusted analyses (supplementary tables 4 to 6 in web appendix 1), effect sizes were generally reduced in single or joint pollutant adjusted models. Given the strong relation between exposures and census output area level deprivation, we ran birth weight models without adjustment for Carstairs quintile to check for overadjustment, however, there were only small changes in birth weight coefficients $(<1 \mathrm{~g})$ and the pattern of results was unchanged (not shown). The inclusion of a random intercept for middle layer super output areas (to models adjusted for all other covariates described) resulted in relatively small changes to associations for noise, term LBW, or SGA, but considerable attenuation of associations between air pollutants and term birth weight (-18\% to $-28 \%$ for primary traffic related air pollutants, and $-35 \%$ to $-49 \%$ for pollutants including regional or urban background contributions). 


\begin{tabular}{|c|c|c|c|c|c|c|}
\hline \multirow[b]{2}{*}{ Exposure } & \multicolumn{3}{|l|}{ Term LBW } & \multicolumn{3}{|l|}{ Term SGA } \\
\hline & No & Odds ratio $(95 \% \mathrm{Cl})$ & Pvalue* & No & Odds ratio $(95 \% \mathrm{Cl})$ & Pvalue* \\
\hline \multicolumn{7}{|c|}{ Air pollutant (for each IQR), adjusted for night-time noise: } \\
\hline $\mathrm{NO}_{2}$ & $540 \quad 365$ & $1.03(1.00$ to 1.06$)$ & & 471489 & 1.01 (0.99 to 1.03$)$ & \\
\hline $\mathrm{NO}_{\mathrm{x}}$ & $540 \quad 365$ & $1.03(1.00$ to 1.06$)$ & & 471489 & 1.01 (0.99 to 1.03$)$ & \\
\hline $\mathrm{PM}_{2.5 \text { traffic exhaust }}$ & $540 \quad 365$ & 1.04 (1.01 to 1.08$)$ & & 471489 & 1.02 (1.00 to 1.04$)$ & \\
\hline $\mathrm{PM}_{2.5 \text { traffic non-exhaust }}$ & $540 \quad 365$ & $1.02(1.00$ to 1.05$)$ & & 471489 & 1.01 (0.99 to 1.02$)$ & \\
\hline $\mathrm{PM}_{2.5}$ & $540 \quad 365$ & 1.06 (1.01 to 1.12$)$ & & 471489 & 1.03 (1.00 to 1.06$)$ & \\
\hline $\mathrm{PM}_{10}$ & $540 \quad 365$ & $1.03(0.99$ to 1.07$)$ & & 471489 & 1.00 (0.98 to 1.03$)$ & \\
\hline $\mathrm{O}_{3}$ & $540 \quad 365$ & $0.96(0.93$ to 0.99$)$ & & 471489 & 0.99 (0.98 to 1.01$)$ & \\
\hline \multicolumn{7}{|c|}{ Night-time noise, $\mathrm{L}_{\text {night }}$ adjusted for $\mathrm{NO}_{2}$ : } \\
\hline$<50 \mathrm{~dB}$ & 162260 & Reference & & 142880 & Reference & \\
\hline 50 to $<55 \mathrm{~dB}$ & 257045 & 0.98 (0.94 to 1.03$)$ & & 224864 & $1.00(0.97$ to 1.02$)$ & \\
\hline 55 to $<60 \mathrm{~dB}$ & 40256 & $1.00(0.93$ to 1.07$)$ & & 34960 & $1.02(0.98$ to 1.06$)$ & \\
\hline 60 to $<65 \mathrm{~dB}$ & 46994 & 1.00 (0.94 to 1.08$)$ & & 40344 & $1.00(0.96$ to 1.04$)$ & \\
\hline$\geq 65 \mathrm{~dB}$ & 33810 & 0.99 (0.91 to 1.08$)$ & & 28441 & $1.02(0.97$ to 1.07$)$ & \\
\hline$P$ value for trend & & & 0.962 & & & 0.432 \\
\hline \multicolumn{7}{|c|}{ Air pollutant (for each IQR), adjusted for daytime noise: } \\
\hline $\mathrm{NO}_{2}$ & 540365 & $1.03(1.00$ to 1.06$)$ & & 471489 & 1.01 (1.00 to 1.03$)$ & \\
\hline $\mathrm{NO}_{\mathrm{x}}$ & 540365 & $1.03(1.01$ to 1.06$)$ & & 471489 & 1.01 (1.00 to 1.03$)$ & \\
\hline $\mathrm{PM}_{2.5 \text { traffic exhaust }}$ & 540365 & 1.04 (1.01 to 1.08$)$ & & 471489 & $1.02(1.01$ to 1.04$)$ & \\
\hline $\mathrm{PM}_{2.5 \text { traffic non-exhaust }}$ & 540365 & $1.02(1.00$ to 1.05$)$ & & 471489 & 1.01 (0.99 to 1.02$)$ & \\
\hline $\mathrm{PM}_{2.5}$ & 540365 & 1.06 (1.01 to 1.12) & & 471489 & $1.03(1.00$ to 1.06$)$ & \\
\hline $\mathrm{PM}_{10}$ & 540365 & $1.03(0.99$ to 1.07$)$ & & 471489 & 1.01 (0.98 to 1.03$)$ & \\
\hline $\mathrm{O}_{3}$ & 540365 & $0.96(0.93$ to 0.99$)$ & & 471489 & 0.99 (0.98 to 1.01$)$ & \\
\hline \multicolumn{7}{|c|}{ Daytime noise, $\mathrm{L}_{\text {Aeq, } 16 \mathrm{hr}}$ adjusted for $\mathrm{NO}_{2}$ : } \\
\hline$<55 \mathrm{~dB}$ & 157491 & Reference & & 138696 & Reference & \\
\hline 55 to $<60 \mathrm{~dB}$ & 265603 & 0.97 (0.93 to 1.02) & & 232346 & 0.99 (0.96 to 1.01) & \\
\hline 60 to $<65 \mathrm{~dB}$ & 40755 & 1.01 (0.94 to 1.09) & & 35334 & 1.01 (0.97 to 1.05) & \\
\hline$\geq 65 \mathrm{~dB}$ & 76516 & 0.98 (0.93 to 1.05$)$ & & 65113 & 0.99 (0.96 to 1.03) & \\
\hline P value for trend & & & 0.802 & & & 0.957 \\
\hline
\end{tabular}

LBW=low birth weight; $S G A=$ small for gestational age; IQR=interquartile range

*P value for linear trend across increasing noise categories.

All sensitivity analyses were conducted on joint air pollutant-noise models. Noise analyses were largely unchanged after excluding those exposed to aircraft or rail noise greater than $50 \mathrm{~dB}$ (not shown). We did not observe interactions between ethnicity and air pollution or road traffic noise exposures for term LBW or SGA. Ethnicity-exposure interactions were observed in term birth weight analyses with both primary traffic related air pollutants $(\mathrm{P}$ value $<0.001)$ and road traffic noise exposures $(\sim 0.028$ for daytime noise, 0.005 for night-time noise), with inverse relations for primary traffic related air pollutants across all ethnic strata (supplementary table 11 in web appendix 1).

The population attributable fraction estimated for term LBW for exposure to $\mathrm{PM}_{2.5}$ over the 25th centile of the distribution (ie, $13.8 \mu \mathrm{g} / \mathrm{m}^{3}$ ) during pregnancy was $3 \%(0 \%$ to $7 \%)$. This $3 \%$ corresponds to $93(0-216)$ cases of term LBW out of a total of 2950 cases each year on average in our London study population which are directly attributable to residential exposure during pregnancy to $\mathrm{PM}_{2,5}>13.8 \mu \mathrm{g} / \mathrm{m}^{3}$.

\section{Discussion}

To our knowledge, this is the largest UK study on air pollution and birth weight, and the first UK study and largest study worldwide of birth weight and noise exposure. We observed that long term exposure during pregnancy to $\mathrm{NO}_{2}, \mathrm{NO}_{\mathrm{x}}, \mathrm{PM}_{2.5}$ overall and specifically from traffic exhaust and non-exhaust sources, and $\mathrm{PM}_{10}$, were all associated with increased risk of LBW at term, across London. There was strong confounding of the relation between road traffic noise and birth weight by primary traffic related air pollutant coexposures, and our results, particularly from generalised additive models, suggest little evidence for an independent exposure-response effect of traffic related noise on birth weight outcomes. Our findings from two air pollutant models suggest that associations between term LBW and air pollutants emitted from vehicle exhausts may be driven by the fine particulate matter $\left(\mathrm{PM}_{2.5 \text { traffic exhaust }}\right)$ component rather than the gaseous $\mathrm{NO}_{\mathrm{x}}$ component.

\section{Strengths and weaknesses of this study}

This study benefits from highly spatially resolved air pollution modelling assigned at address level, and noise levels estimated at address point. For noise particularly, this represents an advance on previous studies which have assigned noise exposure with lower spatial precision (eg, at postcode level, ${ }^{8}$ or according to $50 \mathrm{~m}$ or $250 \mathrm{~m}$ buffers around maternal address, ${ }^{7}$ or based on road proximity) ${ }^{28}$, and consequently reduces 

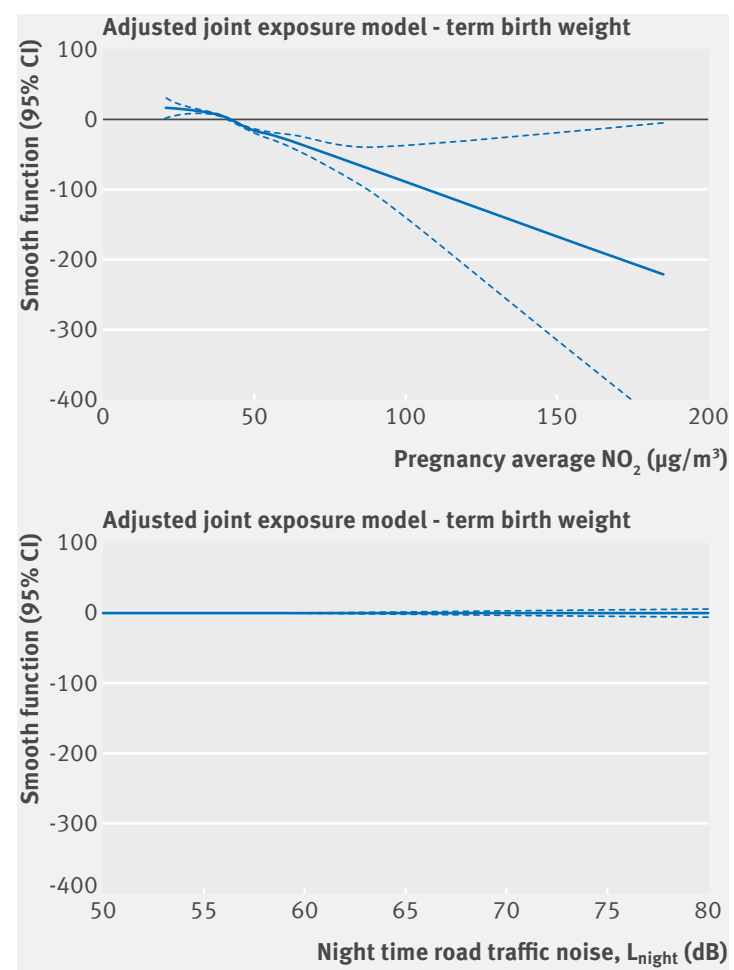

Fig 6 | Adjusted generalised additive model for $\mathrm{NO}_{2}$ and $\mathrm{L}_{\text {night }}$. The plots show smoothing functions with $95 \%$ confidence intervals for the association between term birth weight and $\mathrm{NO}_{2}$ and night-time noise $\left(\mathrm{L}_{\text {night }}\right)$ in joint exposure models. The model is adjusted for sex, maternal age, ethnicity, birth registration type, birth season, birth year, Carstairs quintile (census output area level), tobacco expenditure (census output area level), and gestational age as linear and quadratic terms

potential exposure misclassification, as noise levels may change dramatically over short distances (tens of metres). Nonetheless, the potential for exposure misclassification remains. For air pollution, there may be some exposure misclassification close to sources (where gradients of primary pollutants are steep). However, most people do not live within 10 $\mathrm{m}$ to $30 \mathrm{~m}$ of the centre of a main road so the impact on this study will be low. The percentage of maternal residences in our dataset within $10 \mathrm{~m}$ of a major road (annual average daily traffic (AADT) $>10000$ vehicles) was $0.07 \%$, within $20 \mathrm{~m}$ was $5 \%$, and within $30 \mathrm{~m}$ was $11 \%$. We examined the relation between living within $10 \mathrm{~m}, 20 \mathrm{~m}$, and 30m of a major road and key individual level variables (ethnicity, birth registration type, and maternal age). These variables were not associated with living within $10 \mathrm{~m}$ of a major road. The percentage of mothers living within either $20 \mathrm{~m}$ or 30 $\mathrm{m}$ of a major road was slightly greater (by up to $3 \%$ ) for non-white ethnicities ( $v$ white), unmarried mothers ( $v$ married), and younger ( $v$ older) maternal age groups. However, these percentage differences are very small $(\leq 3 \%)$, so there is no reason to assume that this would introduce serious bias. Most importantly, however, whilst there may be some exposure misclassification between the exposure at the actual address versus the grid point estimate assigned, this should introduce no bias because we have assigned the nearest $20 \mathrm{~m} \times 20$ $\mathrm{m}$ point. To introduce bias we would always have to choose the point on the side of the residence closest to the road and this is unlikely.

The air pollutant model predicted $\mathrm{PM}_{2.5}$ and $\mathrm{PM}_{10}$ slightly more accurately than $\mathrm{NO}_{2}$ and $\mathrm{NO}_{x}$, but the model bias was in the same direction (over prediction) for all these pollutants. Greater model prediction uncertainty for $\mathrm{NO}_{2}$ and $\mathrm{NO}_{x}$ may result in effect estimates for $\mathrm{NO}_{2}$ and $\mathrm{NO}_{\mathrm{x}}$ being more conservative than those for $\mathrm{PM}_{2.5}$ and $\mathrm{PM}_{10}$ and therefore may limit our ability to directly compare the magnitude of effect estimates for $\mathrm{NO}_{2}$ or $\mathrm{NO}_{\mathrm{x}}$ with $\mathrm{PM}_{2.5}$ or $\mathrm{PM}_{10}$.

The noise model is likely to have overestimated and underestimated noise on some minor roads (owing to the constant for traffic on minor roads), but there is no geographical pattern (ie, autocorrelation) in any bias as a result of this, ${ }^{17}$ however, to reduce potential exposure misclassification we categorised noise exposure for analysis. We avoided selection bias by using all birth registration data. Direct measures of individual level smoking or deprivation data were unavailable, but we adjusted for tobacco expenditure and deprivation (Carstairs quintile) at census output area level, as in previous epidemiological studies. ${ }^{29} 30$ We have also adjusted for birth registration type, an individual level variable which relates to both individual level qualifications and housing tenure (and thus socioeconomic status or deprivation) and individual level smoking. ${ }^{31}$ We cannot exclude the possibility of some residual confounding by maternal smoking, passive smoking, or deprivation, but we have adjusted for deprivation and smoking by proxy at individual level, in addition to at area level. Information on parity was not available as part of this study, so we could not adjust for any potential confounding effects directly, but an association between parity and exposure is most likely through deprivation (at area level or individual level), ethnicity, or maternal age, and these have been adjusted for. There is some evidence to suggest that extremes of ambient temperature may be associated with adverse birth outcomes (eg, preterm birth or early delivery and LBW). ${ }^{32-36}$ Meteorological conditions, including ambient temperature, are related to air pollution levels. By adjusting for season we did adjust for general seasonal variation in average temperatures, but we could not adjust for exposure to extreme ambient temperatures as we did not have data on temperature linked to the births data. We could not account for residential mobility during pregnancy $\left(\sim 16 \%\right.$ in $\left.\mathrm{UK}^{37}\right)$, nor exposures away from maternal residence (eg, workplace or transport), indoor air pollution, or exposure modification owing to behaviours (eg, opening windows), or building characteristics (eg, bedroom façade). These could contribute to exposure misclassification.

We were not able to adjust for spontaneous versus medical intervention early delivery (which could influence the outcome indirectly by gestation period), as data on delivery type were not available as part of 
this study from the birth registry or NHS Numbers for Babies (NN4B) datasets. If clinical practice in medical intervention for early delivery varies spatially (eg, between hospitals or owing to cultural factors), this could potentially confound the spatial component of exposure metrics. However, all our epidemiological models included a random effect for small area (middle layer super output areas - average population 8000) specifically to account for underlying spatial patterns in the data, so we do not think this should be a serious issue. Multiple hypothesis tests were performed, so the multiple testing problem (ie, that the probability of a Type 1 error will be greater than 0.05 (5\%)), should be considered when interpreting $P$ values.

\section{Strengths and weaknesses in relation to other studies}

Our single air pollutant model findings are consistent with recent meta-analyses which report increased risk of low birth weight (LBW) and reduced mean birth weight associated with $\mathrm{NO}_{2},{ }^{1} \mathrm{PM}_{2.5}{ }^{38}$ and $\mathrm{PM}_{10}{ }^{\circ}{ }^{1} 39$ Meta-analysis results for $\mathrm{O}_{3}$ are less clear: odds ratio for LBW of 1.01 (95\% confidence interval, 0.82 to 1.25 ) for each $20 \mathrm{ppb}$ increase in pregnancy exposure to $\mathrm{O}_{3} .{ }^{1}$ To our knowledge, only three Californian studies, have examined source specific $\mathrm{PM}_{2.5}$ and birth weight. Converted to the same interquartile range (IQR) $(0.35$ $\mu \mathrm{g} / \mathrm{m}^{3}$ ) scale as our $\mathrm{PM}_{2.5 \text { traffic exhaust }}$ analyses, these studies each report $2 \%$ increased odds of term LBW for $\mathrm{PM}_{2.5}$ from diesel and 3\% to $4 \%$ increased odds for $\mathrm{PM}_{2.5}$ from gasoline, ${ }^{40-42}$ consistent in magnitude with our odds ratio for term LBW of 1.04 (95\% confidence interval, 1.01 to 1.07$)$ for each IQR increase. To our knowledge, no previous study has reported two pollutant models including source specific $\mathrm{PM}_{2.5}$. Our findings, that only $\mathrm{PM}_{2.5}$ traffic exhaust (out of $\mathrm{PM}_{2.5}$ traffic exhaust, $\mathrm{NO}_{2}$, and $\mathrm{NO}_{\mathrm{x}}$ ) showed a consistent elevated risk with mutual adjustment, suggesting that associations between LBW and air pollutants emitted from vehicle exhausts may be driven by the fine particulate matter $\left(\mathrm{PM}_{2.5}\right.$ traffic exhaust $)$ component rather than the gaseous $\mathrm{NO}_{\mathrm{x}}$ component is an important and new contribution to scientific knowledge. Our study also shows associations between LBW and fine particulate matter from road traffic which is not emitted from the vehicle exhaust (ie, brake or tyre wear particles and vehicle induced resuspension of road dust). However, owing to multicollinearity in models containing both $\mathrm{PM}_{2.5 \text { traffic exhaust }}$ and $\mathrm{PM}_{2.5 \text { traffic non-exhaust, we could not }}$ separate potential effects of traffic related exhaust and non-exhaust related $\mathrm{PM}_{2.5}$. The magnitude of association with $\mathrm{PM}_{2.5}$ traffic exhaust was consistently stronger than with $\mathrm{PM}_{2.5}$ traffic non-exhaust, and this could reflect differing chemical constituents (and thus toxicity) of the $\mathrm{PM}_{2.5}$ mixture from different sources.

We found that associations between road traffic noise and term birth weight were strongly attenuated when adjusted for primary air pollutants related to traffic: to null when adjusted for $\mathrm{PM}_{2.5}$ traffic exhaust or $\mathrm{PM}_{2.5 \text { traffic non-exhaust }}$, although after adjustment for $\mathrm{NO}_{2}$ or $\mathrm{NO}_{\mathrm{x}}$ an association between night-time noise and reduced birth weight in the highest exposure category remained, which could possibly reflect a threshold effect. The results of our generalised additive models adjusted for $\mathrm{NO}_{2}$ or $\mathrm{NO}_{x}$, however, do not support an independent association with road traffic noise, or suggest any threshold effect for noise. The most recent systematic review of noise exposure and birth weight found "evidence supportive of associations between LBW and noise exposure" particularly for very high noise levels, but the evidence was inconsistent, ${ }^{4}$ based on 10 occupational studies, four aircraft noise studies, and two traffic noise studies. Three previous studies have examined long term air pollution and noise exposures jointly. ${ }^{7-9}$ Our findings are consistent with a small cohort study $(\mathrm{n}=6438)$ in Barcelona, which suggested elevated risks of term LBW and small for gestational age (SGA) associated with noise and air pollution exposures in single exposure adjusted models, but in a joint exposure model term LBW risk was associated with third trimester $\mathrm{PM}_{2.5}$ (for each 3.6 $\mu \mathrm{g} / \mathrm{m}^{3}$, odds ratio $1.31,95 \%$ confidence interval 1.07 to 1.61), but not noise (for each $6.7 \mathrm{~dB}$ (A-weighted), $0.89,0.71$ to 1.12$){ }^{7}$ Term birth weight was not associated with $\mathrm{NO}_{2}, \mathrm{NO}_{x}$, or road traffic noise, in either fully adjusted single exposure models or joint exposure models in the Danish National Birth Cohort $\left(\mathrm{n}=75\right.$ 166). ${ }^{9}$

Our findings contrast with a registry based study in Vancouver ( $n=68238)$, which found associations between all transportation (road traffic, railway, and aircraft) noise $\left(\mathrm{L}_{\mathrm{den}}\right)$ and reduced term birth weight or LBW which remained after adjustment for $\mathrm{PM}_{2.5}, \mathrm{PM}_{10}$, and primary road traffic air pollution $\left(\mathrm{NO}_{2}\right.$ and $\left.\mathrm{NO}_{\mathrm{x}}\right)$, however, associations for air pollutants were attenuated to null by adjustment for transportation noise. ${ }^{8}$ Road traffic noise showed similar associations with term birth weight or LBW in single exposure models, but road traffic noise adjusted for air pollution was not analysed. ${ }^{8}$ We, however, found an association between the road traffic noise and reduced birth weight remained after adjustment for $\mathrm{PM}_{2.5}$ or $\mathrm{PM}_{10}$ (which include regional and urban background contributions) - one possible explanation is that adjusting for $\mathrm{PM}_{2.5}$ or $\mathrm{PM}_{10}$ did not fully control for confounding of noise by air pollution coexposures from road traffic. This should be noted by other researchers investigating potential health effects of road traffic noise.

Compared with London, the noise distribution in Vancouver was wider ( $\mathrm{L}_{\text {den }}$ mean $60.2 \mathrm{~dB}(\mathrm{~A}$-weighted), range 6.2-89.0), mean air pollution exposures were lower and with less contrast in Vancouver $\left(\mathrm{PM}_{2.5}\right.$ mean $4.1 \mu \mathrm{g} / \mathrm{m}^{3}$, range $0-11.3 ; \mathrm{NO}_{2}$ mean $33.7 \mu \mathrm{g} / \mathrm{m}^{3.5}$, range 0-64.5) and Denmark $\left(\mathrm{NO}_{2}\right.$ median $11.0 \mu \mathrm{g} / \mathrm{m}^{3}$, 5th-95th centiles 7.1-26.3), and air pollutant-noise correlations were lower in Vancouver (correlations with road traffic noise: 0.05 for $\mathrm{NO}_{2}, 0.09$ for $\mathrm{PM}_{2.5}$; and all transportation noise: 0.18 for $\mathrm{NO}_{2}, 0.16$ for $\mathrm{PM}_{2.5}$ ), but higher in Denmark ( 0.47 between $\mathrm{NO}_{2}$ and road traffic noise). ${ }^{89}$ These differences, which could reflect differences in pollutant sources, may contribute to the contrasting findings from Denmark and Vancouver 
compared with our study. In our study the noise model floor means that the minimum modelled value of nighttime noise from road traffic in London was $42.4 \mathrm{~dB},{ }^{17}$ which is higher than the recommended upper limit of exposure of total noise of $40 \mathrm{~dB}$ proposed by the Night Noise Guidelines for Europe. ${ }^{43}$ It is possible that we did not have a sufficiently low noise exposure reference group, to detect small associations between noise and birth weight, above the guideline level.

In the broader context, our findings contrast with reviews of joint air pollution and noise studies which suggest independent effects of road traffic noise on other health outcomes (eg, cardiovascular outcomes), after adjustment for air pollution. ${ }^{44}$ This could reflect different biological pathways between noise and fetal growth versus other health outcomes at later stages of life. The fetus has no direct exposure to the environment, but exposure is mediated through the mother and placenta, and this may modify effects. Threshold effects may be relevant for exposure to noise, and the threshold could vary between health outcomes, possibly being higher for effects on birth weight versus, for example, cardiovascular outcomes. Alternatively, it might reflect differences between studies in the ability to control for confounding by air pollution from road traffic specifically. We did note that associations between noise and birth weight were more strongly attenuated by adjustment for primary road traffic-related air pollutants $\left(\mathrm{NO}_{2}, \mathrm{NO}_{\mathrm{x}}, \mathrm{PM}_{2.5 \text { traffic exhaust }}, \mathrm{PM}_{2.5 \text { traffic non-exhaust }}\right)$ compared with background air pollutants $\left(\mathrm{PM}_{2.5}\right.$ and $\left.\mathrm{PM}_{10}\right)$. This suggests that adjusting for the background pollutants may not fully adjust for the confounding effects of air pollution coexposures directly from road traffic, in our study. With respect to cardiovascular outcomes, it has been noted that "more studies using air pollution indicators specific to road traffic are needed to properly assess if road noise and pollutant effects on CV outcomes are subjected to the confounding effect of one another." ${ }^{45}$

Our results did not give a clear indication as to which trimester could be most influential with respect to air pollution and fetal growth, and previous study findings have been inconsistent on this point. The most recent meta-analyses are suggestive overall of stronger associations for later trimesters between LBW or reduced birth weight and $\mathrm{PM}_{2.5}$ and $\mathrm{PM}_{10}$, 3839 but unclear for $\mathrm{NO}_{2} \cdot{ }^{1}$ One potential explanation for this is that earlier trimester exposures may be more prone to exposure measurement bias from residential mobility (in studies assigning exposure according to maternal residential address at birth), and thus attenuated towards the null. However, there are persuasive findings from a natural experiment of air pollution reductions during the 2008 Bejing Olympics, supporting the importance of the third trimester exposures to air pollution in relation to term birth weight. $^{46}$ This is biologically plausible, as during the third trimester the rate of fetal growth and weight gain increases dramatically and reaches its peak at about week $33 .^{4748}$

We found effect modification by ethnicity of the relation between air pollution and reduced birth weight in line with previous studies, although results for different ethnic groups have been inconsistent. ${ }^{49-54}$ Effect modification by ethnicity could reflect increased susceptibility to the adverse impacts of air pollution, owing to environmental inequality or differing biological susceptibility.

Biological mechanisms in which air pollution or noise may impair fetal growth are not established. Hypothesised mechanisms for air pollution are oxidative stress; endocrine disruption; changes to maternal-placental blood flow and oxygen or nutrition transfer; ${ }^{55}$ placental mitochondrial damage ${ }^{56}$ and placental growth or function, ${ }^{57}$ whilst those for noise are stress triggered endocrine or immune response disruption, plasma catecholamine increase or placental blood flow decrease, ${ }^{4}$ hypertension, ${ }^{5}$ and sleep disturbance. ${ }^{6}$ Convincing evidence that maternal passive smoking during pregnancy is causally related to reduced birth weight, ${ }^{58}$ strongly supports the biological plausibility of an association between ambient air pollution and reduced birth weight, by analogy.

\section{Conclusion}

This study suggests that in Greater London, which has $19 \%$ of all annual births in England and Wales, ${ }^{59}$ air pollution from road traffic is having a detrimental impact upon babies' health, before they are born. We estimate that $3 \%$ of term LBW cases in London are directly attributable to residential exposure during pregnancy to $\mathrm{PM}_{2.5}>13.8 \mu \mathrm{g} / \mathrm{m}^{3}$. Our results suggest little evidence for an independent exposure-response effect of traffic related noise on birth weight, but we cannot rule out that an association might be observed in a study area with a wider range of noise exposures. Our findings should be broadly generalisable to other UK and European cities or urban areas with comparable exposure levels and profiles. At city scale, environmental health policies aimed at reducing road traffic air pollution could reduce the burden of LBW, SGA, and subsequent lifelong morbidity. With the annual number of births projected to continue increasing in London, ${ }^{60}$ the absolute health burden will increase at the population level, unless air quality in London improves.

We thank Margaret Douglass and Peter Hambly of the Small Area Health Statistics Unit (SAHSU) database team for technical support and the TRAFFIC study group for their constructive comments. CACI tobacco expenditure data are Copyright 1996-2014 CACI Limited.

Contributors: MBT, JG, HRA, SDB, and FJK contributed to study conception and design. DF, JG, SDB, DD, HRA, and FJK contributed to exposure assessment. REG, DF, and ALH acquired health and confounder data. RBS contributed to study design, wrote the statistical analysis plan, conducted the data analyses, and drafted the initial report. MBT contributed to the statistical analysis plan, the data analyses, and initial drafting of the report. MB contributed to the study design and statistical analysis plan. All authors contributed to interpreting the analyses and critically revising the article, approved the final draft, and agree to be accountable for all aspects of the work. All authors had full access to all of the data in the study and can take responsibility for the integrity of the data and the accuracy of the data analysis. MBT is the guarantor.

Funding: This work was funded by the UK Natural Environment Research Council, Medical Research Council (MRC), Economic and Social Research Council, Department of Environment, Food and 
Rural Affairs, and Department of Health (DH) (NE/I00789X/1, NE/ 1008039/1) through the cross research council Environmental Exposures \& Health Initiative. The research was part funded by the National Institute for Health Research Health Protection Research Unit (NIHR HPRU) in Health Impact of Environmental Hazards at King's College London in partnership with Public Health England (PHE). The work of the UK SAHSU is funded by PHE as part of the MRC-PHE Centre for Environment and Health, funded also by the UK MRC (MR/ L01341X/1). The views expressed are those of the authors and not necessarily those of the NHS, the NIHR, PHE, or DH. The funders had no role in the study design; collection, analysis, and interpretation of data; writing of the report; or decision to submit the article for publication.

Competing interests: All authors have completed the ICMJE uniform disclosure form at www.icmje.org/coi_disclosure.pdf and declare: no support from any organisation for the submitted work other than those detailed above; no financial relationships with any organisations that might have an interest in the submitted work in the previous three years; no other relationships or activities that could appear to have influenced the submitted work.

Ethical approval: The study used SAHSU data (UK National Births and Stillbirth register data and NHS Numbers for Babies (NN4B)), supplied by the Office for National Statistics. The study was covered by national research ethics approval from the London-South East Research Ethics Committee (reference 17/LO/0846). Data access was covered by the Health Research Authority Confidentiality Advisory Group under Regulation 5 of the Health Service (Control of Patient Information) Regulations 2002 (reference 14/CAG/1039).

Data sharing: No additional data are available.

Transparency: The lead author, MBT, affirms that the manuscript is an honest, accurate, and transparent account of the study being reported; that no important aspects of the study have been omitted; and that any discrepancies from the study as planned have been explained.

This is an Open Access article distributed in accordance with the terms of the Creative Commons Attribution (CC BY 4.0) license, which permits others to distribute, remix, adapt and build upon this work, for commercial use, provided the original work is properly cited. See: http://creativecommons.org/licenses/by/4.0/.

1 Stieb DM, Chen L, Eshoul M, Judek S. Ambient air pollution, birth weight and preterm birth: a systematic review and meta-analysis. Environ Res 2012;117:100-11. doi:10.1016/j. envres.2012.05.007

2 Royal College of Physicians. Every breath we take: the lifelong impact of air pollution. Report of a working party. RCP, 2016.

3 Münzel T, Gori T, Babisch W, Basner M. Cardiovascular effects of environmental noise exposure. Eur Heart / 2014;35:829-36. doi:10.1093/eurheartj/ehu030

4 Ristovska G, Laszlo HE, Hansell AL. Reproductive outcomes associated with noise exposure - a systematic review of the literature. Int J Environ Res Public Health 2014;11:7931-52. doi:10.3390/ ijerph110807931

5 McCowan L, Horgan RP. Risk factors for small for gestational age infants. Best Pract Res Clin Obstet Gynaecol 2009;23:779-93. doi:10.1016/j.bpobgyn.2009.06.003

6 Palagini L, Gemignani A, Banti S, Manconi M, Mauri M, Riemann D. Chronic sleep loss during pregnancy as a determinant of stress: impact on pregnancy outcome. Sleep Med 2014;15:853-9. doi:10.1016/j.sleep.2014.02.013

7 Dadvand P. Ostro B, Figueras F. Residential proximity to major roads and term low birth weight: the roles of air pollution, heat, noise, and road-adjacent trees. Epidemiology 2014;25:518-25. doi:10.1097/ EDE.0000000000000107

8 Gehring U, Tamburic L, Sbihi H, Davies HW, Brauer M. Impact of noise and air pollution on pregnancy outcomes. Epidemiology 2014:25:351-8. doi:10.1097/ EDE.0000000000000073

9 Hjortebjerg D, Andersen AM, Ketzel M, Pedersen M, RaaschouNielsen O, Sørensen M. Associations between maternal exposure to air pollution and traffic noise and newborn's size at birth: A cohort study. Environ Int 2016;95:1-7. doi:10.1016/j.envint.2016.07.003

10 Moser K, Hilder L. Assessing quality of NHS Numbers for Babies data and providing gestational age statistics. Health Stat Q 2008;37:15-23.

11 Carstairs V, Morris R. Deprivation and health in Scotland. Health Bull (Edinb) 1990:48:162-75.

12 Beevers SD, Kitwiroon N, Williams ML, Kelly FI, Ross Anderson H, Carslaw DC. Air pollution dispersion models for human exposure predictions in London. J Expo Sci Environ Epidemiol 2013;23:64753. doi:10.1038/jes.2013.6
13 The London Atmospheric Emissions Inventory. 2010 [Internet]. 2010 [cited 8/1/2015]. Available from: https://data.london.gov.uk/ dataset/london-atmospheric-emissions-inventory-2010.

14 Beevers S, Dajnak D. Traffic Project Supplementary Files. Air pollution Model. KCLurban model description, evaluation and outputs 2015 [Available from: http://www.kcl.ac.uk/lsm/research/divisions/aes/ research/ERG/research-projects/traffic/index.aspx

15 Toledano MB, Nieuwenhuijsen MJ, Best N. Relation of trihalomethane concentrations in public water supplies to stillbirth and birth weight in three water regions in England. Environ Health Perspect 2005;113:225-32. doi:10.1289/ehp.7111

16 Smith RB, Edwards SC, Best N, Wright J, Nieuwenhuiisen MJ, Toledano MB. Birth Weight, Ethnicity, and Exposure to Trihalomethanes and Haloacetic Acids in Drinking Water during Pregnancy in the Born in Bradford Cohort. Environ Health Perspect 2016:124:681-9. doi:10.1289/ehp.1409480

17 Gulliver J, Morley D, Vienneau D. Development of an open-source road traffic noise model for exposure assessment. Environ Model Softw 2015;74:183-93doi:10.1016/j.envsoft.2014.12.022.

18 World Health Organisation. International Classification of Diseases and Related Health Problems. 10th revision, Fifth edition. 2016.

19 Arbuckle TE, Wilkins R, Sherman G). Birth weight percentiles by gestational age in Canada. Obstet Gynecol 1993:81:39-48.

20 Tin W, Wariyar UK, Hey EN. The Northern Neonatal Network. Selection biases invalidate current low birthweight weight-forgestation standards. Br J Obstet Gynaecol 1997:104:180-5. doi:10.1111/j.1471-0528.1997.tb11041.x

21 Cole TJ, Green PJ. Smoothing reference centile curves: the LMS method and penalized likelihood. Stat Med 1992:11:1305-19. doi:10.1002/sim.4780111005

22 Pan H, Cole TJ. LMSchartmaker, a program to construct growth references using the LMS method. Version 2.54. http://www. healthforallchildren.co.uk/. 2011

23 Bonellie S, Chalmers J, Gray R, Greer I, Jarvis S, Williams C. Centile charts for birthweight for gestational age for Scottish singleton births. BMC Pregnancy Childbirth 2008:8:5. doi:10.1186/1471 2393-8-5

24 Olsen IE, Groveman SA, Lawson ML, Clark RH, Zemel BS. New intrauterine growth curves based on United States data. Pediatrics 2010;125:e214-24. doi:10.1542/peds.2009-0913

25 Lim JS, Lim SW, Ahn JH, Song BS, Shim KS, Hwang IT. New Korean reference for birth weight by gestational age and sex: data from the Korean Statistical Information Service (2008-2012). Ann Pediatr Endocrinol Metab 2014;19:146-53. doi:10.6065/ apem.2014.19.3.146

26 Norris T, Johnson W, Farrar D, Tuffnell D, Wright J, Cameron N. Smallfor-gestational age and large-for-gestational age thresholds to predict infants at risk of adverse delivery and neonatal outcomes: are current charts adequate? An observational study from the Born in Bradford cohort. BMJ Open 2015;5:e006743. doi:10.1136/ bmjopen-2014-006743

27 Rockhill B, Newman B, Weinberg C. Use and misuse of population attributable fractions. Am I Public Health 1998:88:15-9. doi:10.2105/AJPH.88.1.15

28 Wu TN, Chen LI, Lai IS, Ko GN, Shen CY, Chang PY. Prospective study of noise exposure during pregnancy on birth weight. Am J Epidemiol 1996;143:792-6. doi:10.1093/oxfordjournals.aje. a008817

29 Nieuwenhuiisen MJ, Toledano MB, Bennett J. Chlorination disinfection by-products and risk of congenital anomalies in England and Wales. Environ Health Perspect 2008;116:216-22. doi:10.1289/ ehp.10636

30 Douglas P, Bakolis I, Fecht D. Respiratory hospital admission risk near large composting facilities. Int J Hyg Environ Health 2016;219:372-9. doi:10.1016/j.ijheh.2016.03.004

31 Graham ICC, Barnard M. Mowlam A, McKay S. Sole and joint birth registration: exploring the circumstances, choices and motivations of unmarried parents. Department of Work and Pensions Research Report No 463. Leeds: Her Majesty's Stationery Office by Corporate Document Services; 2007.

32 Basu R, Malig B, Ostro B. High ambient temperature and the risk of preterm delivery. Am J Epidemiol 2010;172:1108-17. doi:10.1093| aje/kwq170

33 Arroyo V, Díaz J, Ortiz C, Carmona R, Sáez M, Linares C. Short term effect of air pollution, noise and heat waves on preterm births in Madrid (Spain). Environ Res 2016;145:162-8. doi:10.1016/i. envres.2015.11.034

34 Auger N, Naimi Al, Smargiassi A, Lo E, Kosatsky T. Extreme heat and risk of early delivery among preterm and term pregnancies. Epidemiology 2014:25:344-50. doi:10.1097/ EDE.0000000000000074

35 Strand $L B$, Barnett AG. Tong S. The influence of season and ambient temperature on birth outcomes: a review of the epidemiological literature. Environ Res 2011;111:451-62. doi:10.1016/j. envres.2011.01.023 
36 Ha S, Zhu Y, Liu D, Sherman S, Mendola P. Ambient temperature and air quality in relation to small for gestational age and term low birthweight. Environ Res 2017;155:394-400. doi:10.1016/j. envres.2017.02.021

37 Tunstall H, Pickett K, Johnsen S. Residential mobility in the UK during pregnancy and infancy: are pregnant women, new mothers and infants ‘unhealthy migrants'? Soc Sci Med 2010;71:786-98. doi:10.1016/j.socscimed.2010.04.013

38 Sun X, Luo X, Zhao C. The associations between birth weight and exposure to fine particulate matter (PM2.5) and its chemical constituents during pregnancy: A meta-analysis. Environ Pollut 2016:211:38-47 doi:10.1016/i.envpol.2015.12.022

39 Lamichhane DK, Leem JH, Lee JY, Kim HC. A meta-analysis of exposure to particulate matter and adverse birth outcomes. Environ Health Toxicol 2015;30:e2015011. doi:10.5620/eht.e2015011

40 Wilhelm M, Ghosh JK, Su J, Cockburn M, Jerrett M, Ritz B. Trafficrelated air toxics and term low birth weight in Los Angeles County, California. Environ Health Perspect 2012;120:132-8. doi:10.1289/ ehp.1103408

41 Laurent O, Hu J, Li L. Sources and contents of air pollution affecting term low birth weight in Los Angeles County, California, 2001-2008. Environ Res 2014:134:488-95. doi:10.1016/j.envres.2014.05.003

42 Laurent O, Hu J, Li L. Low birth weight and air pollution in California: Which sources and components drive the risk? Environ Int 2016; 92-93:471-7. doi:10.1016/j.envint.2016.04.034

43 World Health Organisation. Night Noise Guidelines for Europe. WHO Regional Office for Europe, 2009.

44 Stansfeld SA. Noise Effects on Health in the Context of Air Pollution Exposure. Int I Environ Res Public Health 2015:12:12735-60. doi:10.3390/ijerph121012735

45 Tétreault LF, Perron S, Smargiassi A. Cardiovascular health, traffic-related air pollution and noise: are associations mutually confounded? A systematic review. Int J Public Health 2013;58: 649-66. doi:10.1007/s00038-013-0489-7

46 Rich DQ, Liu K, Zhang J. Differences in Birth Weight Associated with the 2008 Beiijing Olympics Air Pollution Reduction: Results from a Natural Experiment. Environ Health Perspect 2015;123:880-7. doi:10.1289/ehp.1408795

47 Owen P, Donnet ML, Ogston SA, Christie AD, Howie PW, Patel NB. Standards for ultrasound fetal growth velocity. Br J Obstet Gynaecol 1996;103:60-9. doi:10.1111/j.1471-0528.1996. tb09516.x

48 Williams RL, Creasy RK, Cunningham GC, Hawes WE, Norris FD, Tashiro M. Fetal growth and perinatal viability in California. Obstet Gynecol 1982;59:624-32.

49 Bell ML, Belanger K, Ebisu K. Prenatal exposure to fine particulate matter and birth weight: variations by particulate constituent and sources. Epidemiology 2010;21:884-91. doi:10.1097/ EDE.0b013e3181f2f405
50 Darrow LA, Klein M, Strickland MJ, Mulholland JA, Tolbert PE. Ambien air pollution and birth weight in full-term infants in Atlanta, 19942004. Environ Health Perspect 2011;119:731-7. doi:10.1289/ ehp. 1002785

51 Salihu HM, Ghaji N, Mbah AK, Alio AP, August EM, Boubakari I. Particulate pollutants and racial/ethnic disparity in feto-infant morbidity outcomes. Matern Child Health J 2012;16:1679-87. doi:10.1007/s10995-011-0868-8

52 Bell ML, Ebisu K, Belanger K. Ambient air pollution and low birth weight in Connecticut and Massachusetts. Environ Health Perspect 2007;115:1118-24. doi:10.1289/ehp.9759

53 Schembari A, de Hoogh K, Pedersen M. Ambient Air Pollution and Newborn Size and Adiposity at Birth: Differences by Maternal Ethnicity (the Born in Bradford Study Cohort). Environ Health Perspect 2015;123:1208-15. doi:10.1289/ehp.1408675

54 Basu R, Harris M, Sie L, Malig B, Broadwin R, Green R. Effects of fine particulate matter and its constituents on low birth weight among full-term infants in California. Environ Res 2014;128:42-51. doi:10.1016/j.envres.2013.10.008

55 Slama R, Darrow L, Parker J. Meeting report: atmospheric pollution and human reproduction. Environ Health Perspect 2008;116:791-8. doi:10.1289/ehp.11074

56 Clemente DB, Casas M, Vilahur N. Prenatal Ambient Air Pollution, Placental Mitochondrial DNA Content, and Birth Weight in the INMA (Spain) and ENVIRONAGE (Belgium) Birth Cohorts. Environ Health Perspect 2016;124:659-65. doi:10.1289/ehp.1408981

57 van den Hooven EH, Pierik FH, de Kluizenaar Y. Air pollution exposure and markers of placental growth and function: the generation $\mathrm{R}$ study. Environ Health Perspect 2012;120:1753-9. doi:10.1289/ ehp.1204918

58 Office on Smoking and Health (US). The Health Consequences of Involuntary Exposure to Tobacco Smoke: A Report of the Surgeon General. Atlanta (GA): Centers for Disease Control and Prevention (US); 2006. Available from: https://www.ncbi.nlm.nih.gov/books/ NBK44324/

59 Births by mothers' usual area of residence in the UK - 2015 release [Internet]. 2016 [cited 16/11/2016]. Available from: https://www.ons.gov.uk/peoplepopulationandcommunity/ birthsdeathsandmarriages/livebirths/datasets/ birthsbyareaofusualresidenceofmotheruk.

60 Birth trends in London November 2016 [Internet]. 2016 [cited 26/01/2017]. Available from: https://files.datapress.com/london/ dataset/birth-trends-in-london/2016-11-30T11:18:11/update08-2016-birth-trends-london.pdf

\section{Appendix: Supplementary materials}

